\title{
PREDICTION AND OBSERVATION OF STRAIN WAVES IN THE EARTH
}

\section{G. Bykov}

Yu.A. Kosygin Institute of Tectonics and Geophysics, Far East Branch of RAS, Khabarovsk, Russia

Key words: migration of earthquakes; strain waves; lithosphere; sine-Gordon equation; solitary waves; unstable sliding

\section{REVIEW ARTICLE}

Handling Editor: S.A. Bornyakov
Received: March 30, 2018

Revised: July 6, 2018

Accepted: July 23, 2018

For citation: Bykov V.G., 2018. Prediction and observation of strain waves in the Earth. Geodynamics \& Tectonophysics 9 (3), 721-754. doi:10.5800/GT-2018-9-3-0369.

Для цитирования: Быков В.Г. Предсказание и наблюдение деформационных волн Земли // Геодинамика и тектонофизика. 2018. Т. 9. № 3. C. 721-754. doi:10.5800/GT-2018-9-3-0369. 


\title{
ПРЕДСКАЗАНИЕ И НАБЛЮДЕНИЕ ДЕФОРМАЦИОННЫХ ВОЛН ЗЕМЛИ
}

\author{
В. Г. Быков \\ Институт тектоники и геофизики им. Ю.А. Косыгина ДВО РАН, Хабаровск, Россия
}

\begin{abstract}
Аннотация: Теоретическое открытие деформационных волн Земли - одно из наиболее важных событий в геофизике последней трети XX века - послужило мотивацией к развитию физических основ математической теории распространения этих волн и поиску методов их экспериментального обнаружения. В статье кратко представлена история развития концепции деформационных волн Земли, методы наблюдения и свойства деформационных волн, основные типы геологических структур, генерирующих эти волны. Приведены наиболее значительные результаты теоретических, лабораторных и натурных исследований медленной миграции деформаций. В перспективе концепция деформационных волн Земли может кардинально изменить существующие представления о сейсмическом процессе.
\end{abstract}

Ключевые слова: миграция землетрясений; деформационные волны; литосфера; уравнение sin-Гордона; уединенные волны; неустойчивое скольжение

\section{1. ВВЕДЕНИЕ}

Деформационные волны Земли - одно из наиболее ярких предположений в теоретической геофизике последней трети XX века. Успехи теоретических исследований вызвали большой интерес к поиску возможностей экспериментального обнаружения эффектов распространения волн этого типа и, прежде всего, к интенсивному исследованию миграции землетрясений. Именно с попыток объяснить причину направленной миграции землетрясений, обнаруженной Ч. Рихтером в 1958 г. в Северо-Анатолийском разломе в Турции [Richter, 1958], и тем самым разрешить одну из возникших проблем сейсмологии началось активное формирование концепции деформационных волн Земли.

Миграция землетрясений связана с распространением тектонических напряжений, вызывающих дополнительную нагрузку и, как следствие, последовательное возникновение сильных землетрясений в сегментах разломов с высокой концентрацией упругих напряжений. Миграция эпицентров землетрясений на дневной поверхности Земли это внешнее проявление передачи деформаций внутри Земли. Выяснение физических механизмов распространения и перераспределения энергии деформационных процессов, передачи и сброса тектонических напряжений на границах блоков и литосферных плит - важнейшая проблема современной геодинамики.

В рамках одной статьи довольно сложно представить все этапы развития концепции и поиска деформационных волн Земли, поэтому здесь будут кратко рассмотрены наиболее значительные и от- личающиеся друг от друга подходы в моделировании переноса напряжений в Земле и связанные с ним сопутствующие эффекты, а также основные результаты натурных наблюдений и лабораторных экспериментов, которые можно привлечь для доказательства реальности обсуждаемых волн.

Важно обратить внимание специалистов в области геофизики, геомеханики, тектонофизики, а также в смежных разделах наук о Земле на мультидисциплинарную проблему деформационных волн Земли, которая имеет принципиальное значение для физики землетрясений, глобальной геодинамики и оценки сейсмической опасности.

Медленные деформационные волны возбуждаются главным образом естественными процессами в земной коре и литосфере и проявляются в изменениях сейсмической активности и геофизических полей. Блоковая структура земной коры и литосферы существенно влияет на деформационные, сейсмические, фильтрационные и другие процессы. Именно блоковая структура геологической среды приводит к генерированию волн различного типа, в том числе медленных деформационных волн [Bykov, 2008]. Выявление связей между движениями тектонических структур и волновыми медленными деформационными процессами имеет первостепенное значение.

Эта проблема обсуждается почти 50 лет, начиная с публикации В.Эльзассера [Elsasser, 1969]. Прямые инструментальные измерения медленных деформационных волн затруднительны в связи с их очень низкой скоростью и сверхнизкой частотой. Трудность непосредственного обнаружения сверхдлиннопериодных волн деформации состоит 
не только в отсутствии специального типа детекторов или эффективных схем их расположения, которые могли бы надежно регистрировать эти волны, но, прежде всего, в отсутствии адекватной теории, которая давала бы возможность определить предполагаемое место их регистрации.

К настоящему времени деформографическими, геодезическими и гидрологическими измерениями во многих регионах мира выявлена миграция деформаций со скоростью порядка 10-100 км/год и 1-10 км/сут [Kasahara, 1979; Bella et al., 1990; Harada et al., 2003; Kuz'min, 2012; Reuveni et al., 2014; Yoshioka et al., 2015]. Миграция эпицентров землетрясений совпадает по скорости (10-100 км/год) и направлению с перемещением деформаций земной коры [Kasahara, 1979; Barabanov et al., 1988] и гидрологических эффектов [Kissin, 2008].

Накопленные факты указывают на распространение в земной коре волновых деформационных процессов с различными скоростями [Bykov, 2005]. Наиболее полно результаты наблюдений направленной миграции землетрясений, прямых и косвенных натурных измерений деформационных волн или их признаков были представлены в работах [Mogi, 1968; Kasahara, 1979; Barabanov et al., 1988, 1994; Malamud, Nikolaevsky, 1989; Nevsky et al., 1991; Nersesov et al., 1990]. Эти данные служат мощным фундаментом для физического осмысления многих проблем геодинамики и сейсмологии.

\section{2. ИСТОРИЯ РАЗВИТИЯ КОНЦЕПЦИИ И ТЕОРЕТИЧЕСКИЕ МОДЕЛИ ДЕФОРМАЦИОННЫХ ВОЛН ЗЕМЛИ}

В конце 60-х годов XX в. в мире отмечался повышенный интерес геофизиков к измерению и интерпретации деформаций в Земле, связанный с изучением земных приливов, землетрясений и других тектонических процессов. Проведение в 1972 г. в Лондоне специальной международной конференции "A discussion on the measurement and interpretation of changes of strain in the Earth", организованной при поддержке Королевского общества, служит тому ярким подтверждением. Некоторые доклады содержали первые сведения, имеющие непосредственное отношение к деформационным волнам Земли.

К. Касахара [Kasahara, 1973] продемонстрировал записи наклономеров, из которых следовало существование в земной коре деформаций, мигрирующих вдоль Тихоокеанского побережья о. Хонсю с востока на запад с аномально низкой скоростью (около 20 км/год). Обнаруженная пространственная корреляция миграции деформаций с режимом сейсмической и вулканической активности прилегающих территорий давала ключ к пониманию ме- ханизма передачи напряжений в земной коре. В докладе [King et al., 1973] сообщалось о непрерывных наблюдениях в плотной сети деформометров, расположенных вдоль разлома Сан-Андреас в Центральной Калифорнии, и обнаружении асейсмического крипа, скорость перемещения которого не была постоянной и составляла около 10 км/сут или менее. Обсуждался также вопрос об оптимальном размещении датчиков деформаций различного типа для регистрации крипа вблизи разломов. Ф. Франк утверждал, что сеть деформометров, ориентированная под углом $45^{\circ}$ к разлому и расположенная на расстоянии до 10 км от разлома, может фиксировать смещение величиной 1 мм и обеспечить наилучшую регистрацию миграции деформаций [Frank, 1973].

Формирование концепции деформационных (тектонических) волн Земли в значительной степени развивалось на основе двух сделанных к тому времени открытий: миграции очагов сильных землетрясений вдоль глубинных разломов [Richter, 1958; Mogi, 1968] и глобальной тектоники плит [Isacks et al., 1968]. Представления о литосферных плитах, разделенных мощными разломами и подстилаемых вязкой астеносферой, привели к построению трех типов теоретических моделей деформационных волн: 1) моделей слоистых (литосфера - астеносфера) [Elsasser, 1969; Bott, Dean, 1973; Anderson, 1975; Rice, 1980] (рис. 1-4); 2) моделей слоистых с добавлением эффекта изгиба жесткой литосферной плиты [Nikolaevsky, 1983; Nikolaevsky, Ramazanov, 1985] (рис. 5); 3) моделей разломов с вязкой прослойкой между бортами (вязкоупругие) [Savage, 1971; Ida, 1974; Bella et al., 1990] (рис. 6, 7). Эти модели были предназначены для описания медленных волн напряжений, соответствующих миграции сильных землетрясений вдоль трансформных разломов и желобов (впадин).

По мере накопления данных натурных наблюдений и лабораторных экспериментов были обнаружены новые факты, которые невозможно объяснить в рамках линейной теории упругости (вязкоупругости или упругопластичности). Поиски аналогий и построение новых, нелинейных, математических моделей деформирования разломно-блоковых геологических сред были мотивированы именно этими обстоятельствами.

Представляется, что второй этап развития теории деформационных волн Земли начался после опубликования В.Н. Николаевским статьи [Nikolaevsky, 1995], в которой было, по сути, постулировано уравнение sin-Гордона для моделирования в блоковой геологической среде медленных уединенных волн. Признаки этих волн наблюдались в виде миграции аномалий геофизических полей вблизи разломов [Nikolaevsky, 1996]. 


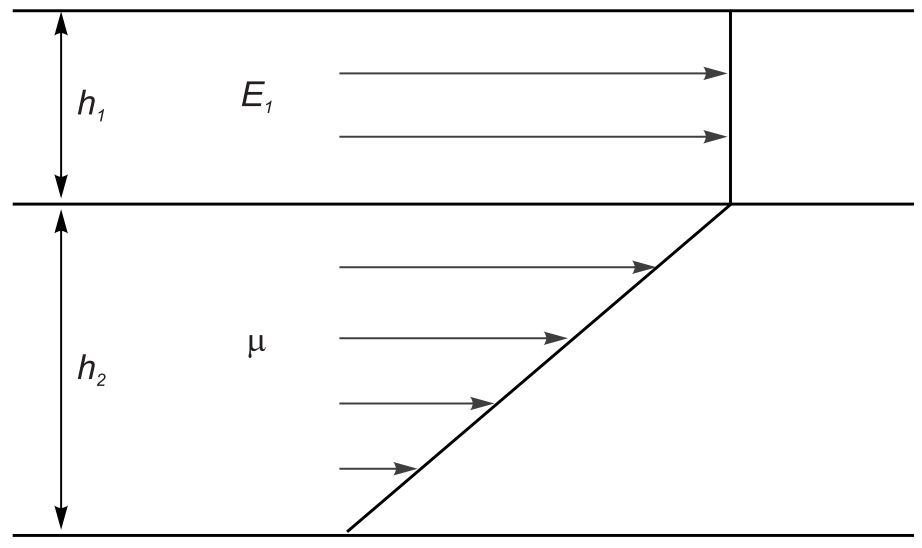

Рис. 1. Модель контактного взаимодействия системы литосфера - астеносфера [Elsasser, 1969].

Fig. 1. Model of contact interaction in the lithosphere - asthenosphere system in the model after [Elsasser, 1969].

Наблюдаемое поведение пространственно-временной миграции современных деформаций в разломных зонах [Kuz'min, 1989, 2012] и динамики сейсмической активности [Spirtus, 2008] имеет качественное сходство с общими представлениями о возбудимых активных средах [Zykov, 1984; Vasil'ev et al., 1979], допускает предположение об автоволновом характере деформационного процесса в разломно-блоковой геосреде и может служить физической мотивацией применения «автоволновых» аналогий при математическом моделировании направленной миграции деформаций и землетрясений.

\section{1. УПРУГОВЯЗКИЕ МОДЕЛИ МЕДЛЕННЫХ ВОЛНОВЫХ ПРОЦЕССОВ}

В 1969 г. американский физик В. Эльзассер впервые рассмотрел механизм передачи напряжений вдоль контакта литосфера - астеносфера. Он предложил модель взаимодействия литосферы твердой плиты мощностью $h_{1}$ с модулем упругости $E_{1}-u$ астеносферы - подстилающего слоя флюида мощностью $h_{2}$ с вязкостью $\mu$ (см. рис. 1). При устойчивом поступательном движении литосферы профиль линейного распределения скорости с глубиной имеет вид, показанный сплошной линией на рис. 1. Скорость $v_{x}$ скольжения литосферной плиты длиной $L$ при горизонтальном напряжении $\sigma_{x}$ вычисляется по формуле $v_{x}=\frac{\sigma_{x}}{\mu} \frac{h_{1} h_{2}}{L}$ [Elsasser, 1969]. Исходя из предположения, что при движении плиты напряжение сдвига $\mu v_{x} / h_{2}=\left(\mu / h_{2}\right) \partial u / \partial t$ на нижней границе плиты уравновешивается общим горизонтальным напряжением $h_{1} \partial \sigma_{x} / \partial x$, $\sigma_{x}=E_{1} \partial u / \partial x$ на краю плиты, В. Эльзассер записал уравнение для осредненного по толщине плиты смещения $u$ [Elsasser, 1969, 1971]:

$$
\begin{gathered}
\frac{\partial u}{\partial t}=\alpha \frac{\partial^{2} u}{\partial x^{2}}, \\
\alpha=\frac{h_{1} h_{2} E_{1}}{\mu} .
\end{gathered}
$$

Уравнение (1) имеет вид уравнения диффузии или уравнения теплопроводности. Ключевым моментом модели является вязкое сцепление между литосферой и астеносферой, характеризуемое параметром $\mu / h_{2}$, который в общем случае зависит от длины волны возмущения. Из стандартного решения уравнения диффузии следует, что среднее расстояние, на которое возмущение распространяется за время $t$, задается величиной $x=2 \sqrt{\alpha t}$. Вычисленная скорость скольжения плиты $v_{x}$ имеет порядок $1 \mathrm{~cm} /$ год, что хорошо согласуется с данными современных GPS-измерений в различных регионах мира [Bird, 2003; Kreemer et al., 2014].

Физически «прозрачная» модель Эльзассера отличалась простотой и наглядностью и практически сразу была использована для описания миграции деформаций и землетрясений [Bott, Dean, 1973; Anderson, 1975], а в дальнейшем - и для объяснения сопутствующих эффектов [Baranov, Lobkovsky, 1980; Baranov et al., 1989; Rydelek, Sacks, 1988; Press, Allen, 1995; Pollitz et al., 1998].

М. Ботт и Д. Дин [Bott, Dean, 1973] впервые применили модель Эльзассера (1) - (2) при исследовании миграции напряжений на границах литосферных плит и ввели термин «stress or strain waves». Стандартными методами решалась задача по определению реакции упругой плиты конечной длины $L$ на приложение давления $P_{0}$ на одном конце плиты (см. рис. 2). Конец плиты при $x=0$ считался фиксированным и представлял собой границу сжатия. Давление $P_{0}$ мгновенно «включалось» на конце

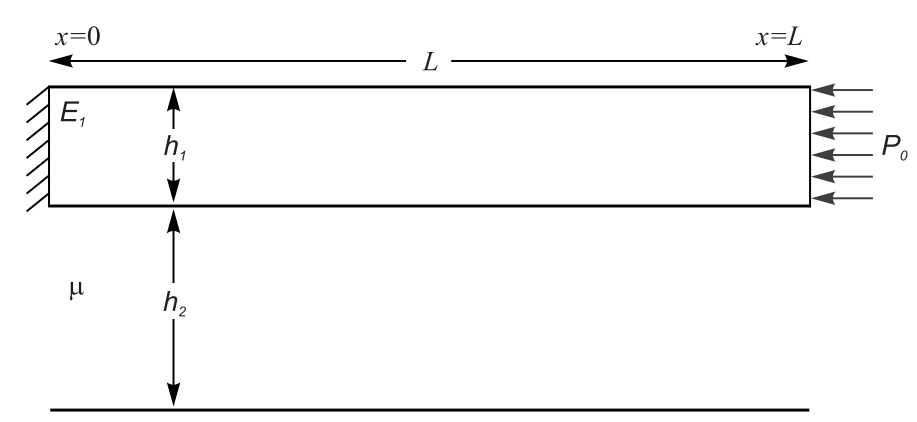

Рис. 2. Модель возбуждения волн напряжения в системе литосфера - астеносфера [Bott, Dean, 1973].

Fig. 2. Model of stress wave exitation in the lithosphere asthenosphere system [Bott, Dean, 1973]. 


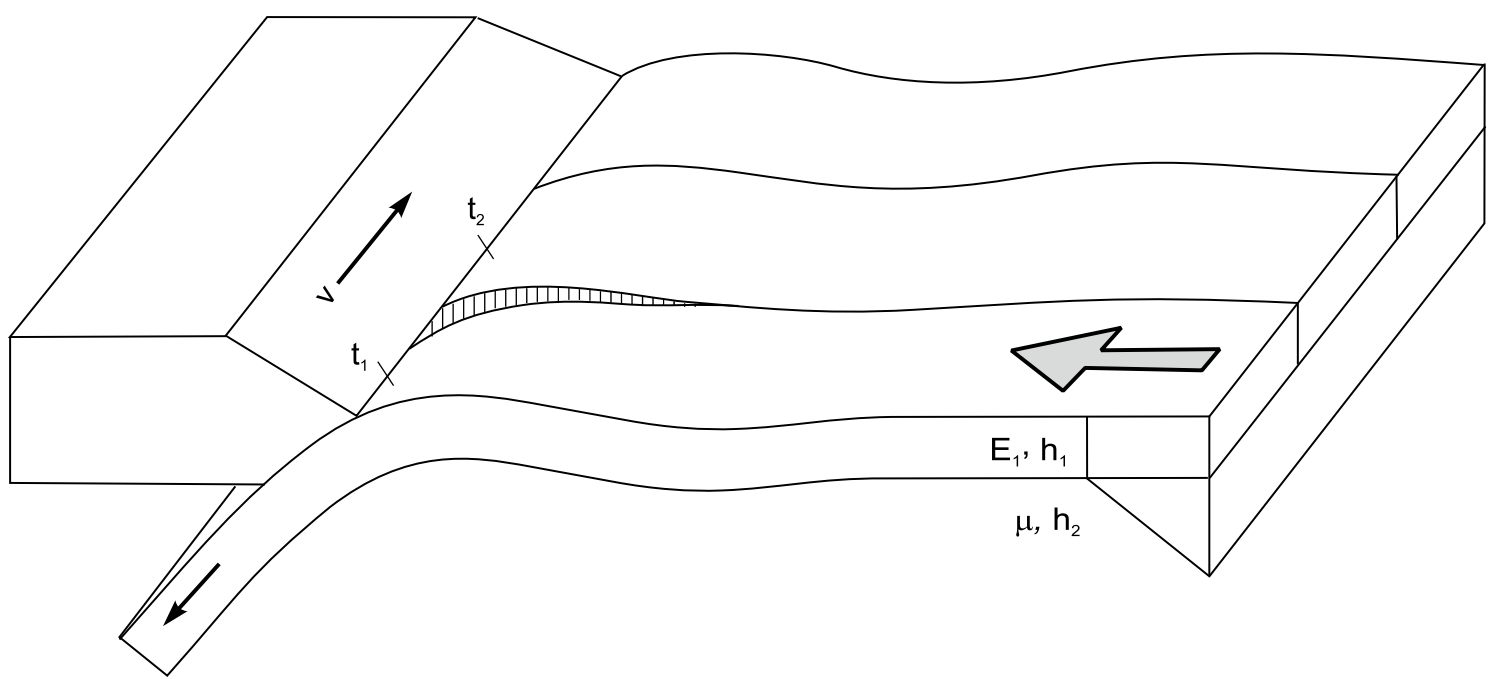

Рис. 3. Модель миграции землетрясений в зоне субдукции [Anderson, 1975].

Fig. 3. Model of earthquake migration in the subduction zone [Anderson, 1975].

плиты $x=L$ в момент времени $t=0$. Уравнение (1) было решено при выбранных начальных: $u=0$ при $t=0 \quad(0 \leq x<L)$ и граничных: $u=0$ при $x=0 \quad(t>0)$ и $(\partial u / \partial x)_{x=L}=-P_{0} / E_{1}, t>0$ условиях.

Предполагая, что давление на границе плиты изменяется как $P=P_{0} \sin \omega t$ с периодом $T=2 \pi / \omega$, и выбрав решение уравнения (1) в виде

$$
\begin{aligned}
& u(x, t)=-\frac{P_{0}}{\sqrt{2} k E_{1}} e^{-k x} \cos \left(\omega t-k x+\frac{\pi}{4}\right), \\
& k=\sqrt{\frac{\omega}{2 \alpha}},
\end{aligned}
$$

М.Ботт и Д.Дин получили для скорости волны напряжений вдоль литосферной плиты выражение

$$
v=\frac{\omega}{k}=\sqrt{2 \alpha \omega}=2 \sqrt{\frac{\pi E_{1} h_{1} h_{2}}{\mu T}} .
$$

Моделирование показало, что приложенное напряжение на границе плиты не может мгновенно воздействовать на всю плиту, но диффузно рассеивается в ней в течение $10^{3}-10^{6}$ лет. Основным фактором, вызывающим медленную миграцию напряжений, является вязкость астеносферы. Согласно (4), скорость волны напряжения зависит от физических свойств литосферы и астеносферы, периода волны и при характерных параметрах континентальной верхней мантии составляет 10-100 км/год.

Д. Андерсон [Anderson, 1975] обобщил модель Эльзассера с целью выяснения механизма миграции землетрясений в зоне субдукции и оценил скорость волны напряжения вдоль островной дуги в 50-170 км/год. Волна деформации генерируется в зоне субдукции и распространяется со скоростью $v$ вдоль разлома по простиранию погружающейся плиты (см. рис. 3). При выбранных параметрах модели Эльзассера $\left(h_{1}=50\right.$ км, $h_{2}=200$ км, $\mu=5 \times 10^{18}$ Па.с, $E_{1}=10^{11}$ Па) скорость переноса сдвиговой деформации по прошествии времени $t_{1}=1$ год равна $v=170$ км/год и уменьшается до $v=50$ км/год после прохождения расстояния в 520 км за $t_{2}=10$ лет. Эти расчеты соответствуют данным о скоростях миграции землетрясений [Mogi, 1968; Yoshida, 1988; Kuznetsov, Keilis-Borok, 1997; Molchanov, Uyeda, 2009].

Дж. Райс [Rice, 1980] модифицировал модель Эльзассера, заменив ньютоновскую реологию вязкой астеносферы на максвелловскую реологию вязкоупругого тела. Введение этой поправки было необходимо, чтобы учесть то обстоятельство, что астеносфера реагирует на быстрые нагрузки $\left(t<\tau=\mu / E_{1}\right)$ как упругое тело, а в низкоскоростном пределе $(t \geq \tau)$ отклик астеносферы на нагрузку будет, как и в модели Эльзассера, только вязким.

Модель [Rice, 1980] применима для математического описания скольжения по контакту плит (разлому) двух типов: сброс и надвиг. Здесь представлен вариант модели (5) - (6), когда скольжение имеет характер сброса, что удобно для сравнения с моделью Эльзассера:

$$
\begin{aligned}
& \frac{\partial u}{\partial t}=\left(\alpha+\beta \frac{\partial}{\partial t}\right)\left\{(1+v)^{2} \frac{\partial^{2} u}{\partial x^{2}}+\frac{\partial^{2} u}{\partial y^{2}}\right\}, \\
& \alpha=\frac{h_{1} h_{2} E_{1}}{\mu}, \beta=b \approx\left(\frac{\pi}{4}\right)^{2} h_{1},
\end{aligned}
$$

где $b$ - эффективная длина кратковременного упругого сцепления; $v$ - коэффициент Пуассона; $\beta / \alpha$ - время релаксации для модели Максвелла. Для интервалов времени $t \gg \beta / \alpha \approx 1.5-15.0$ лет 


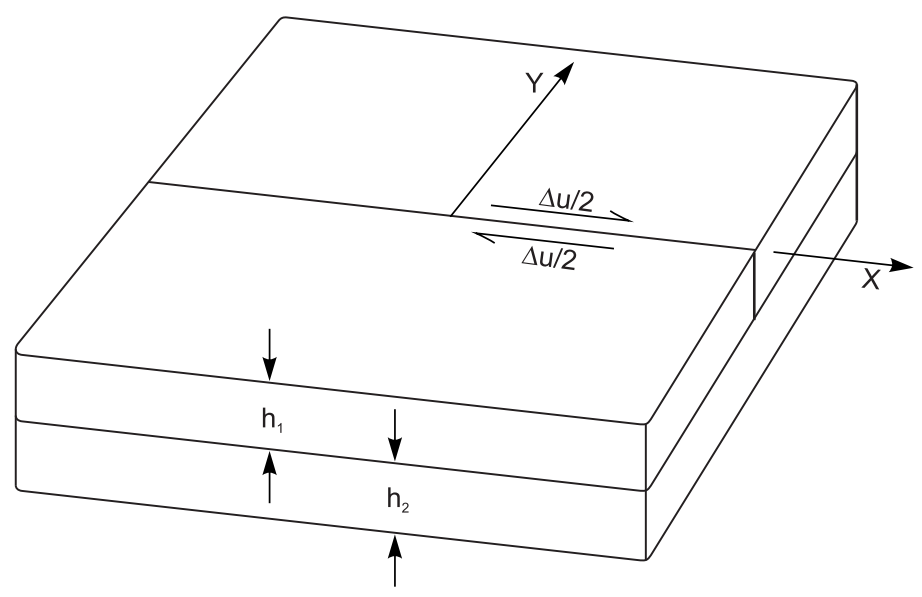

Рис. 4. Модель возбуждения волны напряжения при подвижке в разломе и ее распространения внутрь плиты [Rice, 1980].

Fig. 4. Model of stress wave excitation during shearing along the fault and wave propagation inside the plate [Rice, 1980].

вязкоупругая модель (5) - (6) переходит в вязкую модель Эльзассера (1) - (2).

Уравнение (5) моделирует, по сути, распространение деформационного фронта в литосфере. Смещение в плите (см. рис. 4) для больших промежутков времени записывается в виде [Rice, 1980]:

$$
u(y, t)=(\Delta u / 2) \operatorname{erfc}(y / 2 \sqrt{\alpha t})
$$

откуда следует, что скольжение распространяется внутрь плиты в виде диффузионной волны.

Модель [Rice, 1980] была дополнена и применена для анализа распространения деформационных фронтов через кору и литосферу [Lehner et al., 1981]. Было, в частности, показано, что сцепление между литосферой и астеносферой контролирует пространственно-временное распределение цепочки последовательных сильных землетрясений вдоль границ литосферных плит (трансформных разломов). Из модели также следует, что перенос напряжений осуществляется и от границ вглубь плит, что может служить одним из объяснений возникновения внутриплитных землетрясений и их миграции. Однако миграция внутриплитных землетрясений происходит более сложным образом и зависит от взаимодействия систем разломов [Liu et al., 2011]. Впоследствии двумерный вариант модели [Lehner et al., 1981] использован при моделировании аномального движения земной коры, обнаруженного GPS-наблюдениями в центральной части о. Хонсю (Япония) [Takahashi, Seno, 2005].
Дальнейшая модификация модели Эльзассера состояла в учете латеральной неоднородности литосферы [Albarello, Bonafede, 1990]:

$$
\frac{\partial u}{\partial t}=\frac{h_{2}}{\mu} \frac{\partial}{\partial x}\left(h_{1} E_{1} \frac{\partial u}{\partial x}\right)
$$

Основные особенности этой модели заключаются в том, что утонение литосферы обеспечивает высокие амплитуды диффузионного напряжения, а скорость миграции напряжений возрастает с увеличением толщины литосферы. Это, кстати, может служить объяснением причины столь широкого диапазона значений скорости миграции землетрясений в различных сейсмоактивных регионах.

В.Н. Николаевский [Nikolaevsky, 1983] дополнил модель Эльзассера новым элементом - изгибом литосферной плиты (см. рис. 5), что привело к строгой математической теории распространения деформационных (тектонических) волн. В моделях других исследователей [Rice, 1980; Lehner et al., 1981; Dragoni et al., 1982] этот очевидный эффект не учитывался. Введение вертикальных подвижек, связанных с изгибом литосферы, существенно меняет сценарий эволюции тектонических движений. Результирующая система уравнений записывается для смещений и литосферы вдоль контакта с астеносферой (9) и для вертикальных смещений $\eta$ на контакте астеносфера - литосфера (10) в виде:

$$
\begin{aligned}
& \frac{\partial u}{\partial t}=\frac{\alpha}{\left(1-v^{2}\right)} \frac{\partial^{2} u}{\partial x^{2}}-\frac{\partial}{\partial t}\left(h_{2} \frac{\partial \eta}{\partial x}+\Phi\right)+\left(v_{0}+w_{0}\right), \\
& \frac{\partial \eta}{\partial x}+\frac{E_{1} h_{1}^{3}}{12 \gamma\left(1-v^{2}\right)} \frac{\partial^{4} \eta}{\partial x^{4}}+\frac{\partial^{2}}{\partial x^{2}}\left(\frac{N}{\gamma} \frac{\partial \eta}{\partial x}\right)=\frac{2 \mu}{\gamma h_{2}}\left(\frac{\partial \Phi}{\partial t}+w_{0}\right),
\end{aligned}
$$

где $\Phi$ - ассоциированные перетоки вещества астеносферы; $\partial Ф / \partial t$ - скорость напорного потока; $v_{0}$ стационарная скорость сдвига литосферы относительно астеносферы; $w_{0}$ - стационарная скорость астеносферы; $N-E_{1} h_{1}\left(1-v^{2}\right)^{-1} \partial u / \partial x-$ действующая на литосферу сжимающая сила; $\gamma=\rho_{1} g-$ удельный вес литосферной плиты.

Двумерная модель (9) - (10) взаимодействия литосферы и астеносферы за счет вертикальных смещений и вязких касательных напряжений на их контакте дает в качестве решений либо периодические волны малой интенсивности (стоячие и диффузионные), либо уединенные волны [Nikolaevsky, 1983; Nikolaevsky, Ramazanov, 1985].

Энергия уединенных тектонических волн пополняется из стационарного астеносферного потока, возникающего при подвижке литосферы по астеносфере, и компенсирует вязкие потери. Это служит физическим обоснованием автоволнового механизма генерации уединенных тектонических волн. Скорость $v$ и длина $\lambda$ незатухающих тектонических волн определяются скоростью смещения литосферных плит относительно астеносферы $v_{0}$ 


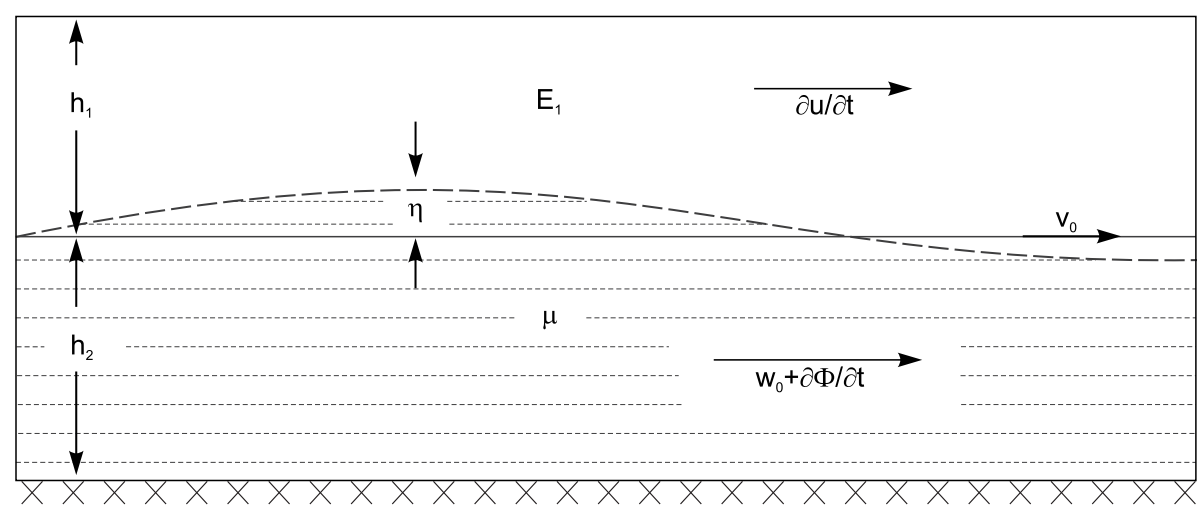

Рис. 5. Схема возбуждения тектонических волн в системе литосфера - астеносфера при изгибе литосферной плиты [Nikolaevsky, Ramazanov, 1985].

Fig. 5. Schematic diagram of tectonic wave excitation in the lithosphere - asthenosphere system during bending of the lithospheric plate [Nikolaevsky, Ramazanov, 1985].

( 10 см/год), прогибом литосферы $\eta(\sim 10 \mathrm{~cm})$ и ее толщиной $h_{1}(\sim 100$ км):

$$
v=\frac{\delta h_{1} v_{0}}{\eta}, \lambda=v \frac{\mu}{E_{1}}=\frac{\delta \mu h_{1} v_{0}}{\eta E_{1}} .
$$

Значение $v$ примерно равно 100 км/год (при величине численного коэффициента $\delta \sim 1)$, причем с уменьшением вязкости астеносферы $\mu$ или с увеличением модуля упругости $E_{1}$ литосферы длина уединенной волны уменьшается, но скорость остается постоянной. Расчеты показали, что тектонические волны имеют характерный период в 2, 3, 6, 11 лет при эффективной ширине порядка 200 км. Распространение этих уединенных волн может объяснить миграцию сейсмичности на дальние расстояния.

Если вертикальные смещения литосферы отсутствуют $(\eta=0)$ и перетоков в астеносфере нет $(\Phi=0)$, то модель (9) - (10) при $v^{2}<<1$ эквивалентна уравнению Эльзассера (1) - уравнению простого горизонтального сжатия-растяжения литосферы.

Б.И. Биргером [Birger, 1989] была предложена модель распространения напряжений в виде волн диффузионного типа. В отличие от модели Эльзассера, литосфера представлена как тонкая упругая пластина, а астеносфера - как вязкоупругое полупространство, неустановившаяся ползучесть которого соответствует реологическому закону Андраде. Скорость волны напряжения в упругой литосфере равна:

$$
v=\frac{h_{1}}{\sqrt{3} B t^{1-\gamma}}
$$

где $\gamma, B$ - реологические параметры; $t$ - время. Параметр $B$ имеет размерность времени в степени $\gamma$ $(c \gamma)$. Для реальных геоматериалов $0<\gamma<1$, для среды Андраде $\gamma=1 / 3$. Тогда выражение для скорости $v$ имеет вид [Birger, 1989]:

$$
v=\frac{h_{1}}{\sqrt{3} B t^{2 / 3}}
$$

При $\gamma=1$ модель (12) переходит в модель Максвелла, $B$ имеет размерность времени (с) и соответствует максвелловскому времени релаксации $\mu / G$, а скорость определяется как $v=h_{1} G / \sqrt{3} \mu$. Зависимость скорости от времени (13) принципиально отличает модель [Birger, 1989] от модели Эльзассеpa c ньютоновской астеносферой: при больших временах напряжения монотонно затухают.

Заметим, что применение нелинейных реологических моделей для описания передачи напряжений в системе литосфера-астеносфера обсуждалось также в работах [Melosh, 1976; Dragoni et al., 1982; Rydelek, Sacks, 1990; Mitlin, Nikolaevsky, 1990].

В модели Дж. Сэвиджа [Savage, 1971] движение блоков земной коры вдоль трансформного разлома представлено в виде потока краевых дислокаций. Перенос напряжения по разлому определен в терминах концентрации $k$ и потока $q$ дислокаций. Скорость деформации пропорциональна потоку дислокаций. Диффузионный механизм играет основную роль в динамике потока дислокаций, кинематическое поведение которого контролируется физическими свойствами зоны разлома. Результирующее уравнение имеет вид [Savage, 1971]:

$$
\frac{\partial q}{\partial t}=-c \frac{\partial q}{\partial x}+D \frac{\partial^{2} q}{\partial x^{2}}
$$

где $c=\partial q / \partial k$ - скорость, $D$ - коэффициент диффузии. Принципиальный результат заключается в 


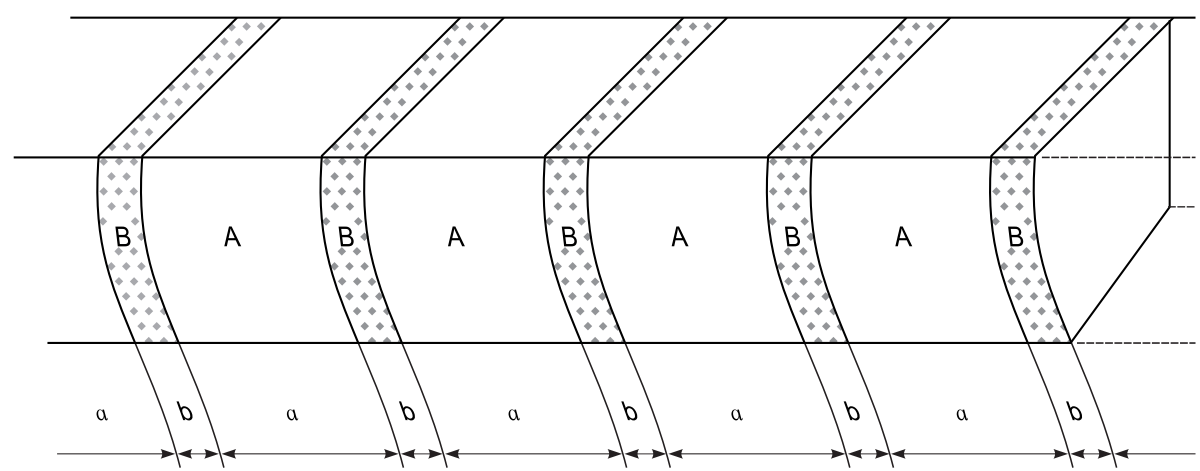

Рис. 6. Структурная модель земной коры [Bella et al., 1990].

| Fig. 6. Structural model of the Earth's crust [Bella et al., 1990].

том, что механизм потока дислокаций приводит к «криповым волнам» (creep waves) вдоль трансформного разлома - волнам напряжений. По расчетам Дж. Сэвиджа, скорость таких волн вдоль трансформного разлома Сан-Андреас составляет порядка 10 км/год, зависит от амплитуды деформации и увеличивается с ее ростом. Согласно гипотезе Дж. Сэвиджа, криповые волны вызывают резкое изменение движения в разломе и связаны с миграцией сильных землетрясений вдоль северо-восточной окраины Тихого океана. По данным о миграции землетрясений было установлено распространение фронта напряжений в направлении с северо-запада на юго-восток вдоль разлома Сан-Андреас со скоростью 30-50 км/год [Malin, Alvarez, 1992].

Ё. Ида $[I d a, 1974]$ получено решение в виде медленно движущегося импульса деформации ("slowmoving deformation pulses") с постоянной скоростью $\nu=G d / 2 \mu(\mu, d-$ вязкость и толщина прослойки; $G$ - модуль сдвига вмещающих горных пород) вдоль разлома. Модель дает скорость импульса от 10-100 км/год до 1-10 км/сут. В статье [Vilkovich, Shnirman, 1982] был выполнен анализ применимости модели [Ida, 1974] и выбора физических параметров для расчета скоростей миграции землетрясений. Модель признана перспективной для объяснения миграции вдоль разломов.

В модели [Bella et al., 1990] блоки (A, а) земной коры разделены «мягкими» ослабленными переходными зонами (B, b) - прослойками (см. рис. 6), которые могут представлять собой трещиноватые флюидонасыщенные среды с модулями упругости, намного меньшими, чем модули материала блоков. Авторы модифицировали неупругую модель Максвелла и предложили следующее соотношение для связи напряжение-деформация [Bella et al., 1990]:

$$
k \frac{\partial^{z} \sigma}{\partial t^{z}}+E \sigma=k E \frac{\partial^{z} \varepsilon}{\partial t^{z}}
$$

где $\sigma, \varepsilon$ - напряжение и деформация; $E$ - модуль упругости (жесткость), $\kappa$ - неупругий параметр, аналог вязкости с размерностью г/(см с $\left.{ }^{2-z}\right)$. Показатель степени $z$ имеет значение $0<z<1$, и при $z=1$ параметр $\kappa$ принимает размерность динамической вязкости $\mu$, а уравнение (15) соответствует модели Максвелла. Мотивация такой замены была обоснована результатами лабораторных низкочастотных измерений [Liu et al., 1976; Caputo, 1979], из которых следует, что классические вязкоупругие модели (Ньютона, Максвелла, Кельвина-Фойгта и др.) неадекватно отражают реологию геоматериалов. Результирующая система уравнений имеет вид [Bella et al., 1990]:

$$
\begin{aligned}
& \sigma_{n}=M \frac{\partial^{2} s_{n}}{\partial t^{2}} \\
& k \frac{\partial^{z} \sigma_{n}}{\partial t^{z}}+E_{b} \sigma_{n}=\frac{k E_{b}}{b} \frac{\partial^{z}}{\partial t^{z}}\left[s_{n+1}+s_{n-1}-2 s_{n}\right] .
\end{aligned}
$$

Здесь $M$ - поверхностная плотность; $\sigma_{n}$ - напряжение, приложенное к $n$-блоку; $s_{n}-$ смещение $n$-блока из положения равновесия; $E_{b}$ - модуль упругости прослойки $B$.

Скорость $v$ миграции возмущений деформаций вдоль цепочки, состоящей из четырех блоков с линейным размером $(a+b)$, равна [Bella et al., 1990]:

$$
v=2(a+b) \frac{\omega}{\pi}
$$

Согласно (18), скорость медленной волны напряжения в блоковой геосреде определяется только геометрическими размерами блоков $a$ и частотой $\omega$ их колебаний. При размерах блоков порядка 10 км и частоте $10^{-5}-10^{-8} \mathrm{c}^{-1}$ скорость имеет значение $\left(10^{-3}-10^{-1}\right)$ м/с или 30 км/год - 10 км/сут, что согласуется с данными многочисленных наблюдений. Напомним, что скорость обычной сейсмической волны $c=(E / \rho)^{1 / 2}$ в земной коре равна 
(a)

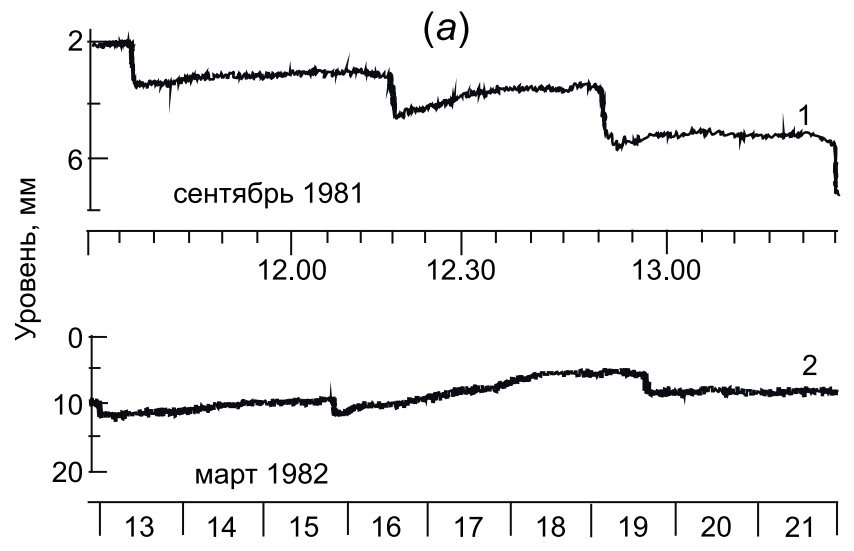

(8)

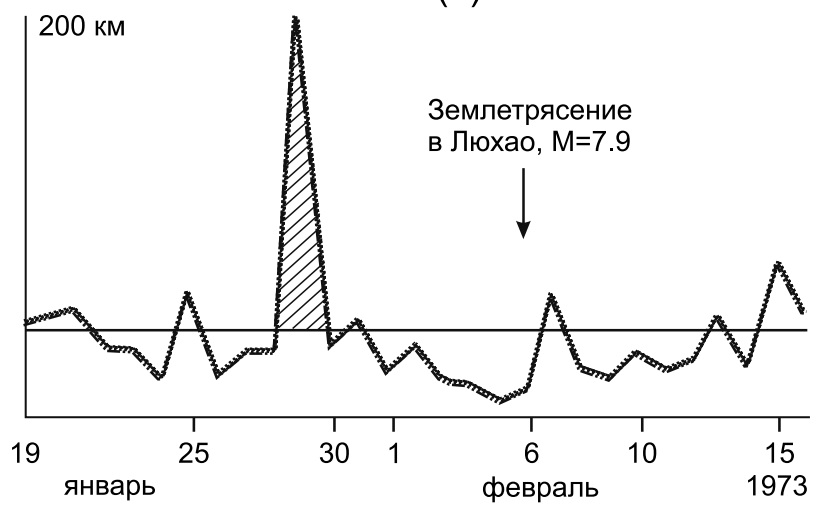

(б)

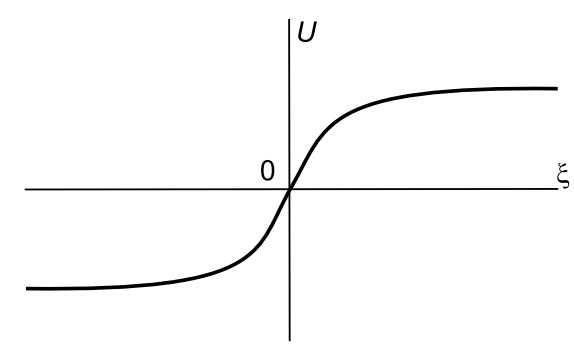

(2)

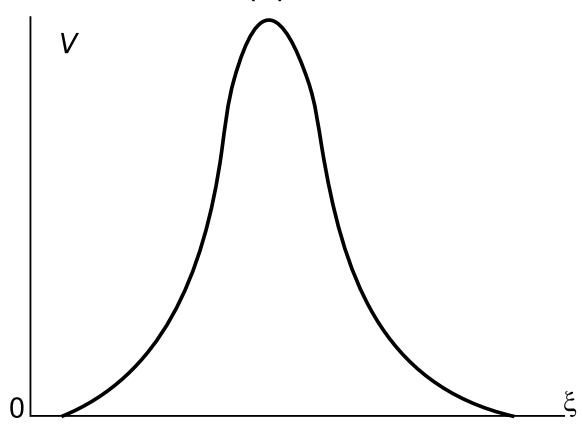

Рис. 7. Косвенные признаки деформационных волн вдоль разломов земной коры. (a) - ступенчатые колебания уровня воды в скважинах Ким (1) и Ашт (2) вблизи Ашхабада [Nikolaevskiy, 1998]; (б) - решение уравнения sinГордона, $U$ - кинк; (в) - концентрация радона, измеренная в Гузане перед землетрясением в Люхао [Nikolaevskiy, 1998]; (2) - решение уравнения $\sin -$ Гордона в виде солитона $V$ (первая производная от функции $U$ ).

Fig. 7. Indirect indicators of strain waves along the crustal faults. (a) - gradual step fluctuations of the water level in the Kim (1) and Asht (2) wells near Ashgabat [Nikolaevsky, 1998 ]; (6) - solution of the sine-Gordon equation, $U$ - kink; ( 8 ) - radon concentration measured in Guzan before the Lujao earthquake [Nikolaevskiy, 1998]; (2) - solution of the sine-Gordon equation: soliton $V$ (the first derivative of the $U$ function).

2.5-7.5 км/с и зависит только от физических свойств геосреды, в которой распространяется волна.

Кстати, полученное из теории [Nikolaevsky, $R a$ mazanov, 1986] выражение для скорости деформационных волн в системе литосфера-астеносфера при наличии глубинного разлома имеет вид [Nevsky et al., 1989]:

$$
v=\omega\left(\frac{2 h_{1} h_{2} G_{1}}{G_{2}}\right)^{1 / 2} A_{0}
$$

и содержит, так же как и (18), геометрические размеры системы (толщину литосферной плиты $h_{1}$ и астеносферы $h_{2}$ ). Скорость определяется еще и безразмерным отношением модулей сдвига в литосфере $G_{1}$ и астеносфере $G_{2}$, частотой $\omega$ волны и безразмерным коэффициентом $A_{0}$.

\section{2. УРАВНЕНИЕ SIN-ГОРДОНА И ПЕРЕДАЧА ТЕКТОНИЧЕСКИХ НАПРЯЖЕНИЙ}

Вязкоупругие или упругопластические модели [Elsasser, 1969; Rice, 1980; Lehner et al., 1981; Dragoni et al., 1982; Birger, 1989] не могут описать медленные тектонические деформации в виде уединенных волн и не учитывают блоковую структуру земной коры и литосферы, поэтому В.Н. Николаевским была сконструирована упругая модель, отвечающая блоковому строению литосферы или земной коры с учетом инерции кинематически независимых поворотов микроплит или поворотных колебаний блоков горной породы, составляющих тела разломных зон земной коры. Соответствующая модификация механики Коссера привела к балансу моментов количества движения в виде уравнения sin-Гордона [Nikolaevsky, 1995]. Одно из аналитиче- 
ских решений уравнения sin-Гордона - кинк. Теперь известно, что эти кинки (перегибы) являются солитонами в строгом математическом смысле [Scott, 2007]. Форма этих функций совпадает с наблюдаемыми записями аномалий геофизических полей (см. рис. 7) перед землетрясениями. Кроме того, солитон sin-Гордона может останавливаться и вновь приходить в движение без изменения своей топологии, что дает возможность моделировать динамику разломов. И, наконец, кинк при движении (медленном скольжении) излучает линейные волны (фононы), которые могут служить аналогом эпизодического сейсмического тремора в зонах субдукции [Gershenzon et al., 2011].

Эвристический подход при конструировании уравнения sin-Гордона для блоковой среды позволил объяснить медленное перераспределение напряжений в земной коре за счет волн деформации (отдельных скачков или уединенных волн), движущихся со скоростями, на много порядков меньшими, чем скорости обычных сейсмических волн [Nikolaevsky, 1995].

C тех пор уравнение sin-Гордона активно применяется при моделировании динамики разломов, движения блоков земной коры, генерирующих деформационные волны, при интерпретации наблюдаемых при этом сейсмических и деформационных эффектов [Garagash, 1996; Mikhailov, Nikolaevskii, 2000; Bykov, 1996, 2000, 2001, 2008; Vikulin, Ivanchin, 1998; Gershenzon et al., 2009, 2011, 2014, 2015].

Уравнение sin-Гордона, впервые полученное при описании дислокаций в кристаллах [Kontorova, Frenkel, 1938], а затем успешно использованное в теории ферромагнетизма, квантовой оптике, физике элементарных частиц, в биологии [Scott, 2007; Braun, Kivshar, 2008; Aero et al., 2009], имеет несколько качественно отличающихся аналитических решений в виде фононов, кинков, бризеров, уединенных волн, быстрых и медленных кноидальных волн. В задачах сейсмологии и геомеханики каждому из этих решений соответствует свой ход эволюции системы блоков и разломов [Bykov, 2000].

Необходимо подчеркнуть, что строго получить уравнение $\sin$-Гордона из уравнений механики сплошной среды, а значит, и медленные уединенные волны, наблюдаемые в разломно-блоковой геосреде, без дополнительных предположений не представляется возможным. Уравнение sin-Гордона в геомеханике и сейсмологии строго не выводится, так же как не выводятся уравнения Ньютона в классической механике, уравнения Максвелла в электродинамике, уравнение Шредингера в квантовой механике. Эти уравнения являются эвристическими. Справедливость применения уравнения sin-Гордона к геосредам доказывается тем, что вытекающие из него следствия согласуются с резуль- татами экспериментов, т.е. уравнение является обобщением опытных данных, что, в свою очередь, придает ему характер закона природы.

Математические модели механизмов поворота и скольжения блоков земной коры, соответствующие уравнению sin-Гордона, включают в качестве переменных угол поворота фрагментов горных массивов [Nikolaevsky, 1995, 1996; Garagash, 1996; Garagash, Nikolaevsky, 2009] или смещение блоков, локализованных вдоль разломов [Bykov, 2000; Gershenzon et al., 2009, 2011; Gershenzon, Bambakidis, 2014, 2015]. Более подробно с математическими моделями деформационных волн Земли, которые соответствуют классическому и возмущенному уравнению sin-Гордона, можно ознакомиться, например, в обзорах [Bykov, 2014, 2015].

Здесь лишь кратко представим последние достижения, связанные с применением уравнения $\sin$-Гордона при исследовании тектонической активности особого типа - кратковременного медленного скольжения в зонах субдукции, сопровождаемого сейсмическим тремором (episodic tremor and slow slip - ETS).

Скорость миграции тремора вдоль разломов в различных зонах субдукции, удаленных друг от друга на многие тысячи километров, практически одинакова и в среднем равна 10 км/сут [Obara, 2002; Shelly et al., 2007; Beroza, Ide, 2011]. ЕTS возникают с четкой регулярностью во времени, и в различных зонах субдукции этот интервал составляет около 3-18 месяцев [Obara, 2002; Lowry, 2006]. В качестве примера на рис. 8 [Brudzinski, Allen, 2007] показана миграция максимума активности сейсмического тремора вдоль контакта континентальной плиты и погружающейся океанической плиты Хуан де Фука. Этот максимум сопровождает асейсмическое медленное скольжение по разлому на глубине около 40 км и перемещается со скоростью порядка 1-10 км/сут, что следует из расчетов по смещению пика кривой (сдвиг по фазе) от станции РСС до станции MGB: v=96.7 км/13.2 сут $=7.3$ км/сут.

В цикле статей Н. Гершензона с коллегами [Gershenzon et al., 2009, 2011; Gershenzon, Bambakidis, $2014,2015]$ показано, что уравнение sin-Гордона является «подходящим инструментом» для описания широкого спектра наблюдаемых особенностей обычных и «медленных» землетрясений, миграции медленного скольжения и сейсмического тремора.

В статье [Gershenzon et al., 2009] на основе качественной аналогии между движениями на границах литосферных плит и процессами пластической деформации в кристаллах (модель ФренкеляКонторовой) предложена эвристическая модель распространения неупругих волн напряжений вдоль трансформных разломов. Предполагается, что перемещение плиты вдоль разлома происходит 


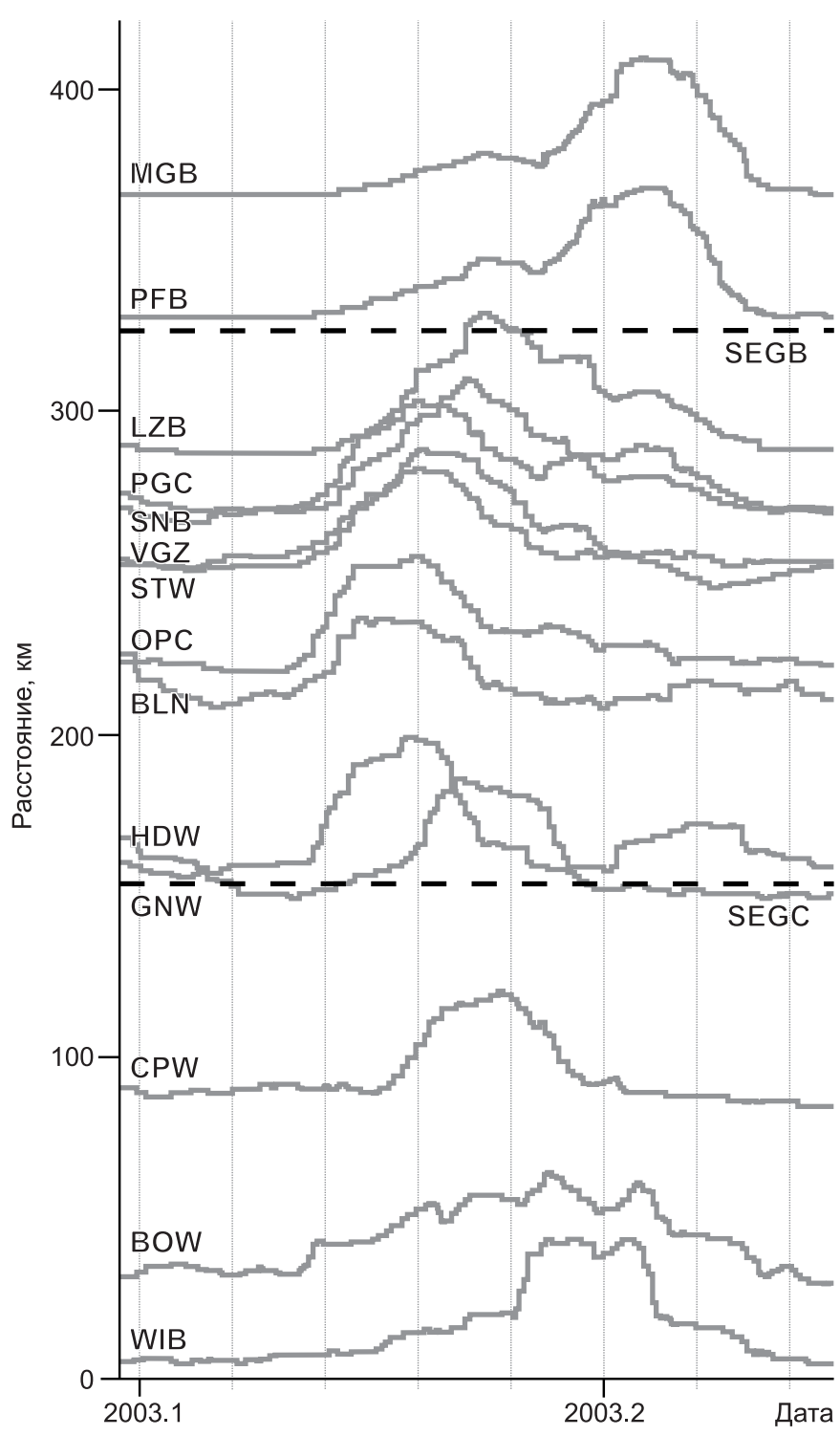

Рис. 8. Эволюция максимума активности сейсмического тремора вдоль контакта погружающейся океанической плиты Хуан де Фука и континентальной плиты (H=40 км) [Brudzinski, Allen, 2007].

Fig. 8. Evolution of the maximum activity of the seismic tremor along the contact of the submerging Juan de Fuca oceanic plate and the continental plate $(\mathrm{H}=40 \mathrm{~km})$ [Brudzinski, Allen, 2007].

вследствие движения дислокаций вдоль границы плиты (термин «дислокация» используется здесь в представлении модели Френкеля - Конторовой). Дислокации перемещаются последовательно «полускачками». Энергия упругости «накапливается» в таких дислокациях. Средняя плотность дислокаций пропорциональна средней деформации на границе плиты, а средняя скорость дислокаций соответствует скорости волны деформации.

Модель соответствует классическому уравнению sin-Гордона:

$$
\begin{aligned}
& \frac{\partial^{2} u}{\partial x^{2}}-\frac{\partial^{2} u}{\partial t^{2}}=\sin u, \\
& u=2 \pi u^{\prime} / b, t=t^{\prime} c A / b, x=x^{\prime} A / b,
\end{aligned}
$$

где $u^{\prime}$ - смещение плиты в направлении $x^{\prime}$ (вдоль разлома); $t^{\prime}$ - время; $b$ - расстояние между «зацеплениями» на плоскости разлома; $c$ - скорость продольной сейсмической волны в земной коре с плотностью $\rho$; $A$ - безразмерный эмпирический коэффициент.

Решениями уравнения (20) при $|U|<1$, $0 \leq m \leq 1$ являются периодические функции:

$$
\begin{aligned}
& u=\arcsin [ \pm \operatorname{cn}(-\beta \xi)], \\
& \varepsilon=\partial u / \partial x=2 \beta \cdot \operatorname{dn}(\beta \xi), w=\partial u / \partial t=2 \beta U \operatorname{dn}(\beta \xi), \\
& \xi=x-U t, \beta=\left[m\left(1-U^{2}\right)\right]^{-1 / 2}, k=\frac{\pi \beta}{2 K(m)} .
\end{aligned}
$$

Функция (21) описывает медленные кноидальные волны - последовательность импульсов с пространственным периодом $2 m\left(1-\beta^{2}\right)^{1 / 2} K(m)$, где $K(m)$ - полный эллиптический интеграл первого рода, $m$ - модуль эллиптической функции Якоби. Безразмерные производные по координате $\varepsilon$ и по времени $w$ - это безразмерные деформация и скорость скольжения; $U$ - безразмерная скорость дислокаций (в единицах с); $k$ - волновое число (в единицах $A / b)$.

Из решений модели (20) следует, что величина скорости неупругих волн является экспоненциальной функцией напряжений и изменяется от нескольких км/с во время землетрясения до 10 км/сут, 10-100 км/год в течение постсейсмического и межсейсмического периодов. Расчеты показывают, что скорость волн деформации после «землетрясения» обратно пропорциональна времени. Число афтершоков уменьшается со временем по этой же зависимости (закон Омори). Отсюда следует физическая интерпретация фундаментального эмпирического закона Омори: афтершоки вызываются волнами деформации, генерируемыми землетрясением [Gershenzon et al., 2009].

Из теоретической физики известно, что при малых возмущениях кинк уравнения sin-Гордона является устойчивым образованием и при движении испускает фононы - волны малой амплитуды, а затем восстанавливается [Peyrard, Kruskal, 1984; Braun, Kivshar, 1998]. Этот результат и был использован в качестве аналогии при построении модели миграции медленного скольжения и тремора [Gershenzon, Bambakidis, 2014].

В рамках модели [Gershenzon, Bambakidis, 2014] основные решения возмущенного уравнения sinГордона - солитоны (кинки) и ангармонические ко- 
лебания (фононы) - интерпретированы как импульсы скольжения и сейсмический тремор, соответственно. Сейсмический тремор (излучение фононов) может возникать вследствие ускорения или замедления импульса скольжения (кинка), взаимодействия импульса скольжения с большими неровностями границы плит, воздействия внешнего возмущения напряжения на границы плит.

При учете только последнего фактора модель соответствует возмущенному уравнению sin-Гордона [Gershenzon, Bambakidis, 2014]:

$$
\frac{\partial^{2} u}{\partial t^{2}}-\frac{\partial^{2} u}{\partial x^{2}}+\sin u=\sum_{S}^{0}-f
$$

где $\sum_{S}^{0}, f$ - внешнее сдвиговое напряжение и сила трения на единицу площади (в единицах $\mu A /(2 \pi))$. Если искать решение в виде бегущей волны $u=u(x-U t)=u(\xi)$ с безразмерной скоростью $U$, то при $U^{2}>1,0 \leq m \leq 1$ решением уравнения (22) является фононная мода с начальной фазой движения $\xi_{0}$ [McLaughlin, Scott, 1978]:

$$
u=2 \arcsin \left[\sqrt{m} \operatorname{sn}\left(\frac{\xi-\xi_{0}}{\sqrt{U^{2}-1}}, m\right)\right]
$$

Модель предсказывает генерацию излучения (23) в диапазоне частот, определяемом параметрами разлома, и возбуждение колебаний резонансного типа внутри разлома в некоторых диапазонах глубин. Модель объясняет сложную картину миграции тремора со скоростью около 10 км/сут и «быстрого» тремора ( 50 км/час). Тремор является внутренним откликом разлома на внешнее воздействие.

В случае $U^{2}<1$ решением уравнения (22) будет локализованная волна в виде возмущенного кинка (солитона):

$$
u_{0}(x, t, U, X)=4 \operatorname{arctg} \exp \left[ \pm\left(\frac{x-\int_{0}^{t} U d t^{\prime}-X}{\sqrt{1-U^{2}}}\right)\right]
$$

где $X$ - начальное положение (координата) центра солитона. Взаимодействие между фононом и кинком, т.е. между двумя модами (23) и (24), возможно, если слагаемые в правой части уравнения (22) не равны нулю.

Динамика импульса скольжения (24) в структурно-неоднородном разломе описывается уравнением [Gershenzon, Bambakidis, 2015]:

$$
\begin{aligned}
& \frac{\partial^{2} u}{\partial t^{2}}-\frac{\partial^{2} u}{\partial x^{2}}+(1+\beta(x)) \sin (1+\varphi(x) u)= \\
& \quad=\sigma_{0}-\left[\alpha_{S} \operatorname{sign}\left(u_{1}\right)+\alpha_{d} u_{t}\right]
\end{aligned}
$$

где $\sigma_{0}$ - внешнее напряжение; $\beta(x), \varphi(x)$ - пространственно локализованные функции, моделирующие структурные неоднородности в виде ше- роховатостей различного размера; $\alpha_{S}, \alpha_{d}$ - параметры статического и динамического трения. Если $\beta=0, \varphi=0$, то импульс скольжения (кинк) перемещается с постоянной скоростью.

Результаты расчетов соответствуют следующему сценарию развития явления ETS [Gershenzon, Bambakidis, 2014, 2015]. Накопившиеся в зоне субдукции напряжения сдвига релаксируют вследствие зарождения и медленного движения импульса скольжения (кинка). Взаимодействие импульса скольжения с неровностями различных размеров приводит к излучению (тремору) внутри разлома.

\section{3. МОДЕЛИ МЕДЛЕННЫХ ДЕФОРМАЦИОННЫХ АВТОВОЛНОВЫХ ПРОЦЕССОВ}

Автоволновая концепция применялась при описании медленных деформационных процессов на основе представлений глобальной тектоники плит [Nikolaevsky, 1983; Malamud, Nikolaevsky, 1989] и принципов синергетики [Androsov et al., 1989; Bazavluk, Yudakhin, 1993]. Как уже упоминалось в разделе 2.1, в работе В.Н. Николаевского [Nikolaevsky, 1983] впервые была показана принципиальная возможность генерирования глобальных тектонических автоволн в системе литосфера-астеносфера. Попытки Т. Оучи с соавторами [Ouchi et al., 1985] формально построить автоволновую модель полей деформаций, приводящих к землетрясениям, не дали положительного результата. Вопрос об автоволновых процессах в литосфере и их математическом моделировании подробно рассматривался в монографии [Malamud, Nikolaevsky, 1989].

В последние годы «автоволновой» подход получил дальнейшее развитие. Ю.О. Кузьминым [Kuz'min, 2012] разработана модель формирования автоволновых деформаций в зонах разломов и построено уравнение нелинейной диффузии смещений земной поверхности. Убедительно показано, что пространственно-временная миграция аномалий современных движений земной поверхности в зонах разломов - следствие автоволновых деформационных процессов в активной, возбудимой геологической среде, являющейся открытой системой, и соответствует по своей структуре уравнению Колмогорова - Петровского - Пискунова. Существование автоволновых структур естественным образом поддерживается притоком энергии региональных и глобальных геодинамических процессов [Kuz'min, 1989; Sidorov, Kuz'min, 1989].

В.Б. Спиртус, исходя из представления, что уединенные волны миграции сейсмичности являются автосолитонами, предложил модель [Spirtus, 2008, $2010,2011]$ возбудимой иерархически-блоковой сейсмической среды (аналог модели активной среды с восстановлением), где в качестве переменных ис- 
пользуется интенсивность сейсмической активности и степень «неконсолидированности» характерного блока среды, а управляющим параметром является средняя скорость деформации, определяющая уровень сейсмической активности. Математическая модель такой среды соответствует модифицированной модели типа Фитцхью - Нагумо [Landa, 1997] и дает возможность объяснить обратную зависимость между скоростью миграции толчков и энергией сейсмических событий, некоторые особенности миграции сейсмичности. Расчеты согласуются с отдельными проявлениями миграции форшоков и акустической эмиссии.

В основу модели П.В. Макарова [Makarov, Peryshkin, 2017] заложена методология синергетики: автоволновые деформационные процессы в геосредах - это явление самоорганизации деформаций на разных масштабных уровнях. Предполагается, что в геологических средах скорости фронтов медленных волн деформаций определяются скоростью генерации дефектов и повреждений при динамическом воздействии на эти среды и регулируются величиной скорости подводимой энергии [Makarov, 2007]. Физический механизм возбуждения медленных деформационных автоволн заключается в потере устойчивости нагруженной упругопластической среды при подвижках на границах блоков земной коры и литосферных плит. Математическая модель включает уравнения механики деформируемого твердого тела, реологические соотношения, задающие скорости накопления неупругих деформаций, а также метод клеточных автоматов. Решения соответствующих систем уравнений дают волны напряжений с широким спектром скоростей.

Анализ упругих, вязкоупругих, упругопластических и автоволновых моделей деформационных волн Земли показывает, что ни одна из них не может объяснить все многообразие наблюдаемых эффектов. Каждая модель пригодна для описания только некоторой части фиксируемых данных, зависящих от многофакторного влияния свойств реальной геосреды и различных трудноопределяемых в натурных условиях параметров, поэтому вряд ли возможно создание универсальных математических моделей. Наиболее результативным может оказаться эвристический подход - подбор по аналогии такого относительно простого механизма, который давал бы возможность в пренебрежении конкретными деталями охватить все качественные особенности явления и моделировать наблюдаемые эффекты.

Дальнейшее развитие концепции деформационных волн Земли, или концепции волновой миграции сейсмичности, может быть связано с моделированием разломно-блоковой геосреды именно в виде автоволновой или автоколебательной (stick- slip) системы, свойства которой во многом определяются состоянием ее внутренних параметров.

\section{3. МЕТОДЫ ОБНАРУЖЕНИЯ ДЕФОРМАЦИОННЫХ ВОЛН И ОСНОВНЫЕ НАБЛЮДЕНИЯ}

Геологические среды моделируются упругими, квазиупругими, пластическими или вязкоупругими телами, которые под действием внешней силы претерпевают деформации объема (растяжение и сжатие) и формы (сдвиг). Если к среде приложить силу, то в ней всегда возникает волна. В физике наиболее общее определение волновых движений заключается в следующем. Волны - это изменения состояния среды (возмущения), распространяющиеся в этой среде и несущие с собой энергию. Основное свойство всех волн, независимо от их природы, состоит в том, что в волне осуществляется перенос энергии без переноса вещества (последний может иметь место лишь как побочное явление) [Prokhorov, 1983].

При описании волновых геодеформационных процессов и анализе результатов натурных измерений волновых проявлений миграции деформаций наиболее приемлемым, по-видимому, можно считать определение, данное Дж. Уиземом: «Волна - любой различимый сигнал, передающийся от одной части среды к другой с некоторой определенной скоростью. Такой сигнал может быть возмущением любого вида: максимумом какой-либо величины или резким ее изменением при условии, что это возмущение четко выделено и что в любой заданный момент времени можно определить его местонахождение. Этот сигнал может искажаться, изменять свою величину и скорость, но при этом он должен оставаться различимым» [Whitham, 1977]. Например, при исследовании волновых движений деформаций земной коры «максимумом какой-либо величины» выбран максимум сдвиговой деформации [Ishii et al., 1978].

Прохождение волны деформаций через геологическую среду сопровождается различными сейсмическими, гидрогеологическими, электрокинетическими, геохимическими и другими эффектами. Методы обнаружения деформационных волн разделяются на косвенные, отражающие волнообразные изменения в геофизических полях вследствие временных вариаций напряженного состояния геологической среды, и прямые, непосредственно регистрирующие миграцию деформаций.

\section{1. КОСВЕННЫЕ И ПРЯМЫЕ НАБЛЮДЕНИЯ ДЕФОРМАЦИОННЫХ ВОЛН ЗЕМЛИ}

Косвенными доказательствами существования деформационных волн служат: направленная ми- 
грация сильных землетрясений [Stein et al., 1997], перемещения сейсмоскоростных аномалий (временные вариации скоростей сейсмических волн, времен пробега и временных невязок, различных параметров сейсмотектонического процесса) [Lukk, Nersesov, 1982; Nevsky et al., 1987], блуждание асейсмичных полос в мантии Земли [Malamud, Nikolaev$s k y, 1989]$, колебательные движения отражающих сейсмических площадок [Bazavluk, Yudakhin, 1993; 1998; Bormotov, Bykov, 1999], миграция аномалий геофизических полей (радоновых, электрокинетических сигналов) [Rudakov, 1992; Nikolaevskiy, 1998; Firstov et al., 2017], миграция эпизодического тремора и медленного скольжения вдоль зон субдукции [Schwartz, Rokosky, 2007]. К косвенным методам регистрации деформационных волн относятся изменения параметров сейсмических, геоэлектрических, геохимических полей.

Прямые признаки деформационных волн - это волновые колебания уровня подземных вод, миграция наклонов и деформаций поверхности. Прямые методы изучения временных вариаций деформаций земной коры включают деформографические [Kasahara, 1979; Ishii et al., 1978, 1980, 1983; Nevsky et al., 1987; Bella et al., 1990; Harada et al., 2003], гидрогеодинамические [Barabanov et al., 1988; Kissin, 2008] и геодезические измерения [Kuz'min, 1989, 2012; Sidorov, Kuz'min, 1989], в том числе и методы измерения деформаций с помощью лазерных светодальномеров [Milyukov et al., 2013].

\section{2. ЛАБОРАТОРНЫЕ ЭКСПЕРИМЕНТЫ}

В 1949 г. Э. Мак-Рейнольдс [McReynolds, 1949] в ходе исследования эффекта Портвена - Ле Шателье совершил фундаментальное открытие медленных волн, сопровождающих прерывистое деформирование: ступенька типа кинка перемещалась вдоль испытуемого образца со скоростью от 0.5 до $80 \mathrm{~cm} / \mathrm{c}$ (рис. 9, a). Возможность генерирования в металлах медленных волн (McReynolds' slow wave) со скоростями порядка нескольких см/с была подтверждена в 1966 г. другими исследователями [Dillon, 1966; Kenig, Dillon, 1966]. При этом также обнаружено изменение формы и уменьшение амплитуды импульса деформации (рис. 9, б), т.е. дисперсия и диссипация - основные свойства волнового процесса.

В том же 1966 г. были опубликованы первые результаты опытов по неустойчивому скольжению (stick-slip) на контакте блоков горных пород и предложено применять этот эффект в качестве аналога очага землетрясения [Brace, Byerlee, 1966]. Опыты с образцами гранита Westerly дали результаты (рис. 9, в) [Scholz et al., 1972], качественно совпадающие с данными для металлов. Позднее экс- перименты stick-slip в условиях двухосного сжатия образцов гранитов Tsukuba позволили с высокой точностью фиксировать эволюцию смещения при неустойчивом скольжении (рис. 10), определить максимум скорости скольжения, который составляет от 1 до 40 см/с [Ohnaka, 2013] и практически равен скорости медленных волн Мак-Рейнольдса в металлах.

Наиболее примечательный результат многочисленных опытов stick-slip с образцами горных пород и различных материалов заключается в том, что перед динамической подвижкой - завершающей стадией каждого цикла stick-slip - всегда возникает волна напряжения, распространяющаяся вдоль контакта блоков (рис. 10). Именно на границе твердых тел при их относительном смещении происходит генерирование деформационных волн различного типа [Bykov, 2008]. По-видимому, система двух контактирующих блоков горных пород может служить простейшим генератором медленных деформационных волн.

В экспериментах stick-slip были обнаружены также уединенные фронты разрушения, перемещающиеся с постоянной скоростью, составляющей всего лишь около $5 \%$ от скорости обычных поперечных волн $V=0.05 V_{\mathrm{s}} \approx 30-60 \mathrm{~m} / \mathrm{c}$ [Nielsen et al., 2010]. Распространение локализованной деформации в виде медленных деформационных волн длиной $10^{-2}$ м и скоростью $10^{-5}-10^{-4} \mathrm{M} / \mathrm{c} \mathrm{выявлено} \mathrm{при}$ сжатии образцов различных горных пород (сильвинит, мрамор, песчаник) [Zuev et al., 2012] и металлов [Zuev, Danilov, 2003].

Совсем недавно в ходе физического моделирования были впервые обнаружены медленные деформационные волны в сдвиговой зоне, формирующейся в упруговязкопластичной блоковой среде [Bornyakov et al., 2016]. Пространственно-временная динамика деформационных волн в сдвиговой зоне определяется ее внутренней разломно-блоковой структурой, а средняя скорость деформационных волн в зависимости от уровня накопленных в зоне напряжений составляет (0.65-4.65) $10^{-3}$ м/с.

\section{3. НАТУРНЫЕ НАБЛЮДЕНИЯ}

Впервые медленная миграция деформаций земной коры была открыта в 60-е годы XX века с помощью водотрубных наклономеров [Asada, 1984]. Затем при анализе данных скважинных тензометров пяти обсерваторий, расположенных на северовостоке Японской островной дуги (о. Хонсю), обнаружена миграция максимума сдвиговой деформации со скоростью 20-40 км/год (рис. 11) [Ishii et al., 1978, 1980]. Математическое моделирование [Sato, 1989] показало для этого региона неплохое совпадение расчетов по обобщенной модели Эльзассера 
(a)

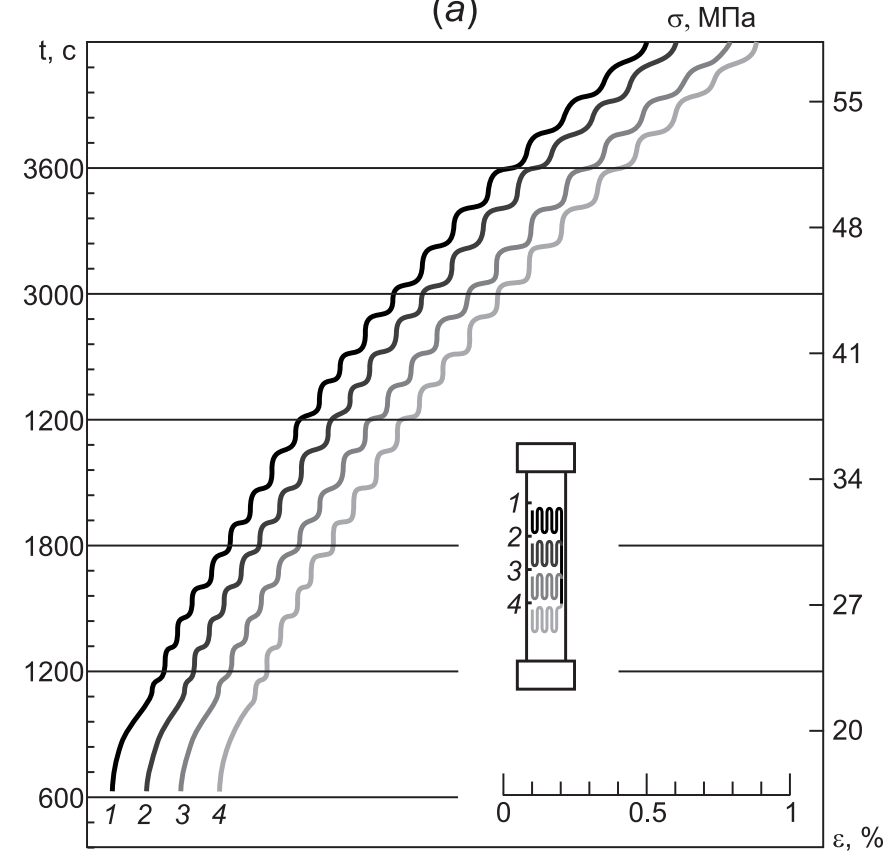

(б)

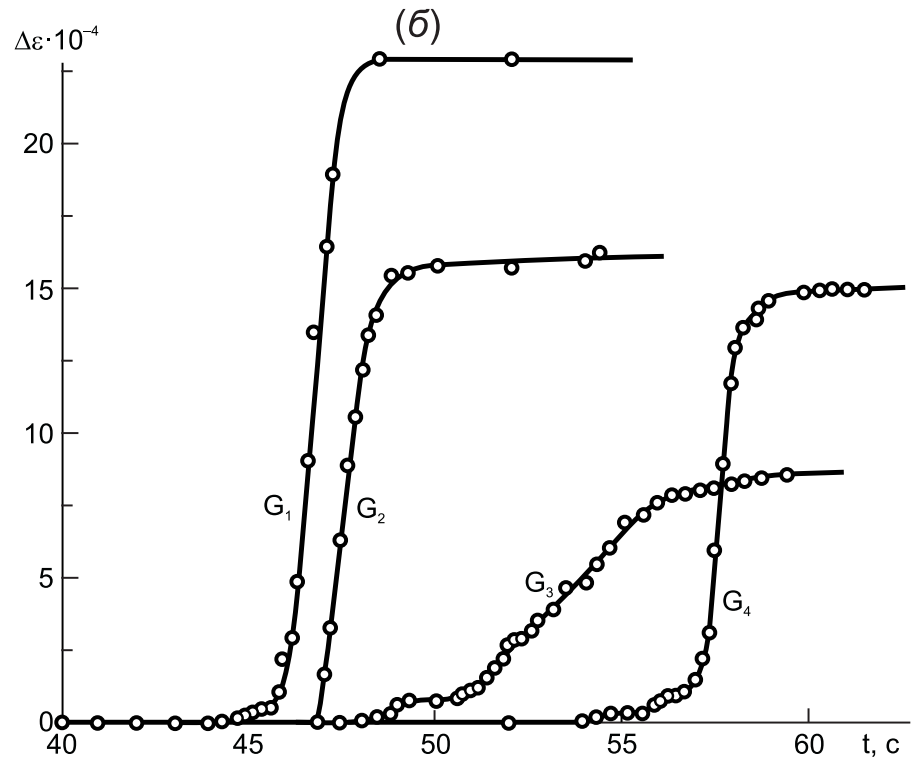

$(8)$

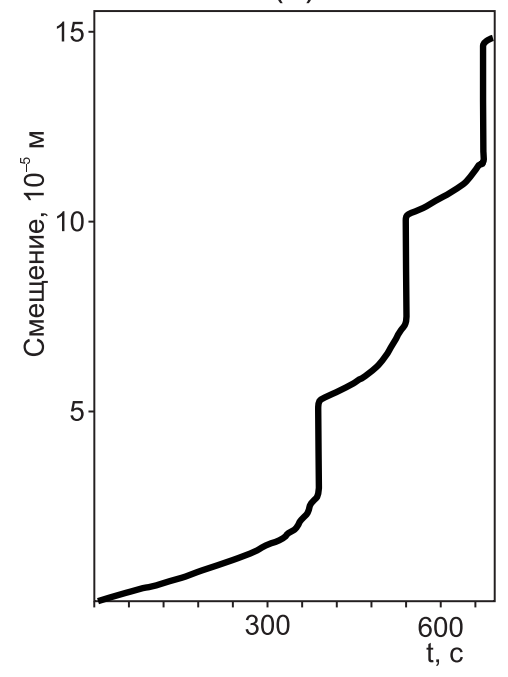

Рис. 9. Эволюция деформации и смещения в металлах и горных породах. (a) - прерывистость деформации $\varepsilon$ по длине образца алюминия в зависимости от напряжения $\sigma$. Номера кривых (1-4) соответствуют номерам сечений (1-4) образца [McReynolds, 1949]; (б) - изменение деформации $\Delta \varepsilon$ во времени, зафиксированное в четырех сечениях образца алюминия [Dillon, 1966]; (в) - изменение смещения при неустойчивом скольжении в образце гранита Westerly [Scholz et al., 1972].

Fig. 9. Evolution of deformation and displacement in metals and rocks. $(a)$ - discontinuity of deformation $\varepsilon$ along the length of the aluminum sample as a function of stress $\sigma$. The numbers of the curves (1-4) correspond to the numbers (1-4) of the sample section [McReynolds, 1949]; (6) - change in deformation $\Delta \varepsilon$ in time, as recorded in four sections of the aluminum sample [Dillon, 1966]; ( 8 ) - change in displacement during unstable slip in the Westerly granite sample [Scholz et al., 1972].

с натурными наблюдениями за «миграцией движений земной коры» и подтвердило эффективность представлений о миграции деформаций в виде медленных волн.

Более высокие скорости миграции коровых деформаций с амплитудами менее 1 см зафиксирова- ны вдоль Японских островов с использованием горизонтальных смещений в 900 пунктах Национальной GPS-сети Японии GEONET с 1994 по 2001 г. [Ito, Hashimoto, 2001]. При этом для каждой GPS-станции эффекты землетрясений и взаимодействия литосферных плит были исключены. 
(a)

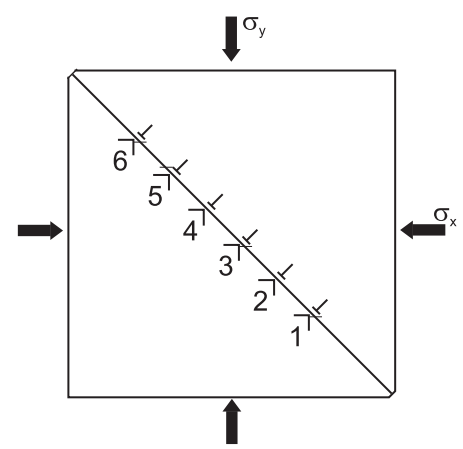

(б)

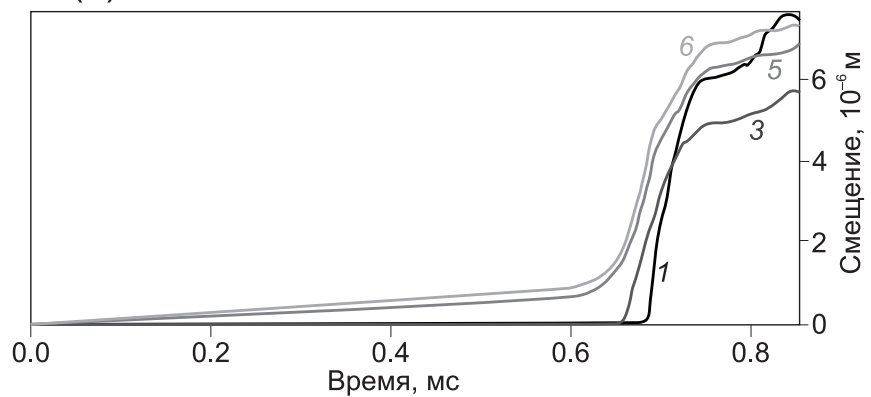

Pис. 10. Схема эксперимента stick-slip в условиях двухосного сжатия $(a)$ и эволюция смещения в различных точках контакта блоков гранита (б). Номера кривых смещений (1-6) (б) соответствуют номерам сенсорных датчиков (1-6) (a), установленных вблизи контакта блоков [Ohnaka, 2013].

Fig. 10. Schematic diagram of the experiment: stick-slip under biaxial compression $(a)$ and evolution of displacement at various points of the contact between the granite blocks (б). In Fig. 10, 6 , the numbers of displacement curves (1-6) correspond to the numbers of sensors (1-6) in Fig. 10, $a$. The sensors were installed near the contact between the blocks [Ohnaka, 2013].

Результаты измерения деформаций в земной коре в период с 1992 по 2000 г. наблюдательной сетью тензометров, установленных в регионе Кюсю, показали миграцию деформаций из зоны субдукции в сторону континента со скоростью 90-140 км/год. Возможная интерпретация этого факта заключается в генерировании импульса деформации вследствие прерывистого движения погружающейся литосферной плиты [Harada et al., 2003].

Таким образом, деформографическими измерениями в различных регионах мира выявлена миграция деформаций со скоростью порядка 10-140 км/год [Kasahara, 1979; Bella et al., 1990; Harada et al., 2003; Yoshioka et al., 2015].

Отметим, что еще в 1979 г. в Китае с помощью чувствительного лазерного тензометра было зарегистрировано движение деформационной волны и предложено использовать этот эффект в качестве предвестника сильных землетрясений [Lu, 1980]. Результаты мониторинга миграции деформаций земной коры и их аномального поведения перед сильными землетрясениями в Японии обсуждались также в статье [Takemoto, 1995].

В работе [Johnston, Linde, 2002] приведены примеры регистрации волн скольжения («slip waves»), которые генерируют когерентные деформации (рис. $12, a$ ) на протяжении нескольких километров поверхности разлома Сан-Андреас (рис. 12, б). Амплитуда волны скольжения составляет около $1 \mathrm{~cm}$, а деформации превышают 10-7. Авторы также отмечают, что основные трудности регистрации волн скольжения, распространяющихся вдоль активных разломов, связаны либо с незначительной амплитудой этих волн ( $<1$ см), либо с очень большим периодом, вследствие чего эти волны не могут быть выделены на фоне «тектонического шума». При этом утверждается, что если бы эти волны перемещались с более высокими скоростями, то они могли бы быть легко зафиксированы скважинными тензометрами, но волны скольжения со скоростью порядка км/год в такой сети не могут быть обнаружены [Johnston, Linde, 2002].

Основные сведения о характеристиках, предполагаемых источниках деформационных волн, методах и условиях их регистрации указаны в табл. 1 и 2.

\section{4. НЕКОТОРЫЕ СВОЙСТВА ДЕФОРМАЦИОННЫХ ВОЛН}

Деформационные волны имеют кинематические и динамические характеристики: скорость, частоту и длину волны, амплитуду (затухание) и форму волны. Наибольший интерес представляют два параметра волн - скорость и затухание.

Весь спектр наблюдаемых скоростей волн деформации изменяется от нескольких км/год до 10 км/сут. Есть даже данные о миграции деформаций (сейсмического тремора) со скоростью 15-150 км/час [Shelly et al., 2007; Beroza, Ide, 2011]. Медленные волны деформации имеют сверхнизкие частоты $f \sim 10^{-8}-10^{-7}$ Гц и большую длину $\lambda \sim 30-300$ км. Главная особенность этих волн заключается в том, что их скорость меньше скорости сейсмических волн на 6-7 порядков, но больше скорости относительного движения литосферных плит в 106-107 раз.

Обладают ли медленные деформационные волны характеристиками, которые присущи обычному волновому процессу, и в частности дисперсией и поглощением?

При изучении деформаций земной коры в регионе Тохоку (Северо-Восточная Япония) обнаружено, что миграция максимума сдвиговой деформации имеет дисперсию скорости: для периода 5.1 года фазовая скорость миграции составила 
(a)

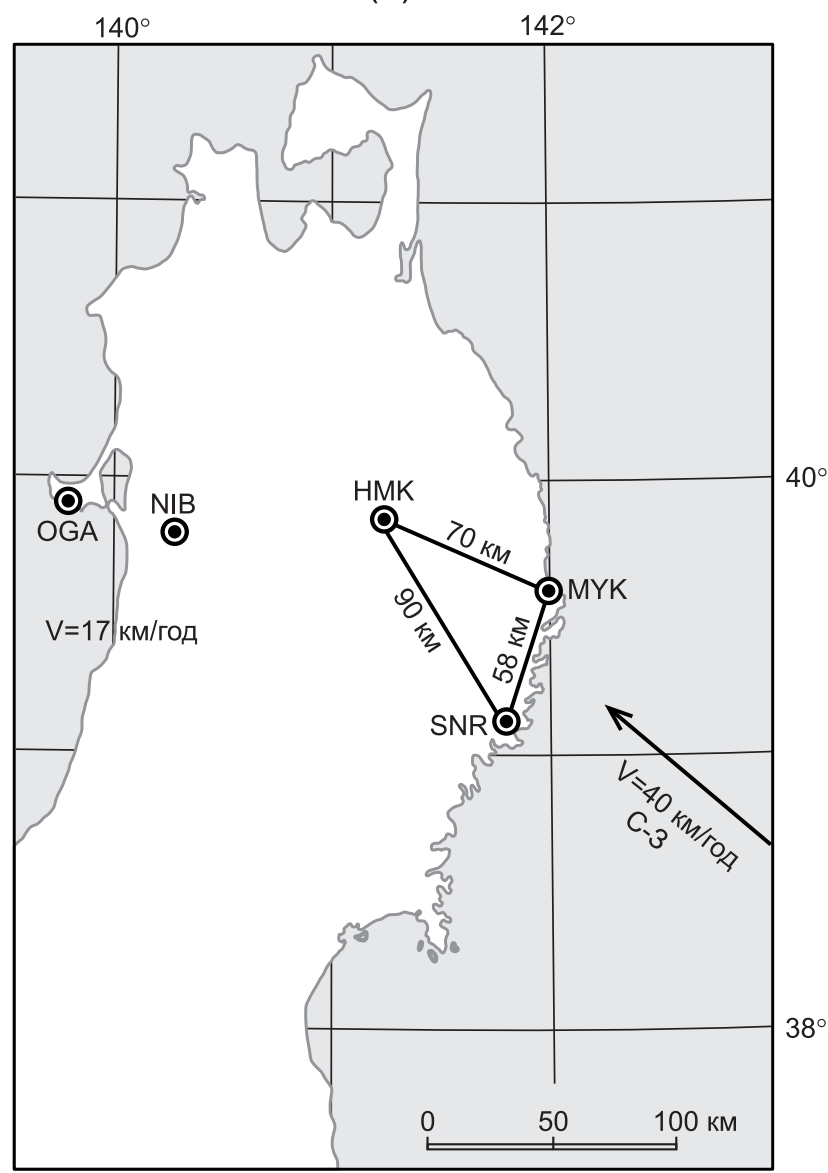

(б)

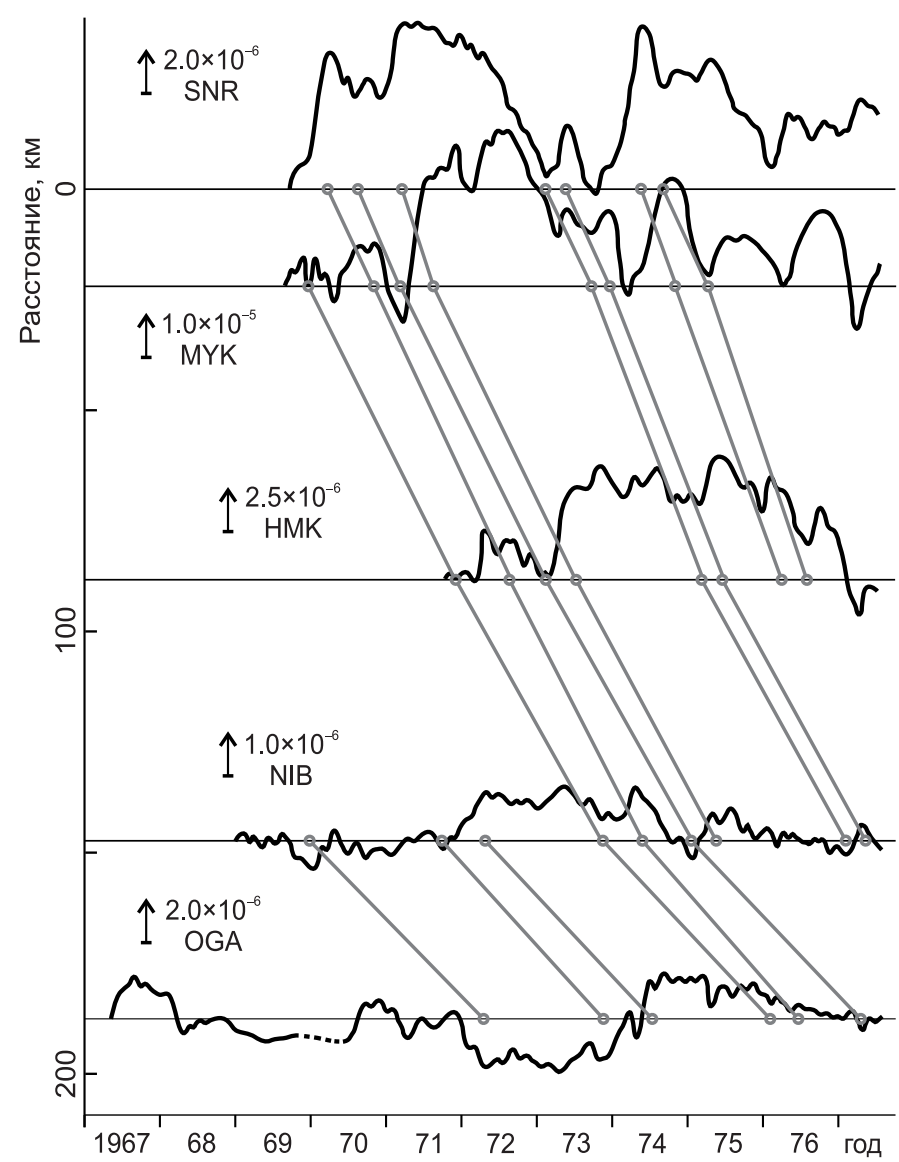

Рис. 11. Пространственно-временное изменение максимума сдвиговой деформации. (a) - направления и скорости миграции максимума сдвиговой деформации; (б) - изменение максимума сдвиговой деформации во времени. Соответствующие фазы соединены линиями [Ishii et al., 1978].

Fig. 11. Spatio-temporal changes in the shear strain maximum. (a) - directions and velocities of migration of the shear strain maximum; (б) - change in the shear strain maximum in time. The corresponding phases are connected by lines [Ishii et al., 1978].

40 км/год и с увеличением периода до 5.8 года уменьшилась до 20 км/год. При этом длина волны в первом случае равна 210 км, а во втором - 110 км [Ishii et al., 1978]. Волны тектонических напряжений примерно с таким же периодом (5-7 лет) выявлены инструментальными сейсмическими наблюдениями в сейсмоактивных и асейсмических районах [Gamburtseva et al., 1982].

В ходе сейсмических и светодальномерных наблюдений в Центральной Калифорнии, Южной Калифорнии и Копетдагском регионе установлены сильная дисперсия скорости $v \sim T^{-1}$ и декременты затухания (0.3-1.0) деформационных волн [Nevsky, 1994]. Для Южной Калифорнии скорость медленных волн деформаций с периодом три года составляла 40 км/год, в Центральной Калифорнии 20 км/год с периодом пять лет [Nevsky et al., 1991], т.е. имеет место нормальная дисперсия.
Дисперсионный характер распространения деформационных волн отмечался и другими исследователями [Barabanov et al., 1988]. Более того, «волновые формы мигрирующей деформации заметно поглощаются при движении» [Kasahara, 1979]. По нашим расчетам коэффициент поглощения деформационной волны (мигрирующего максимума сдвиговой деформации от побережья в глубь региона Тохоку [Ishii et al., 1980]) на частоте $6.0 \times 10^{-9}$ Гц составляет в среднем (10-11-10-10) $\mathrm{M}^{-1}$. Это в $10^{3}-10^{4}$ раз меньше, чем поглощение обычных сейсмических волн в сейсмологическом диапазоне частот (0.01-1.00 Гц), что и позволяет деформационным волнам распространяться на значительные расстояния.

Деформационные волны, так же как и обычные сейсмические (упругие) волны, - это продольные и поперечные волны [Baranov et al., 1989; Lursmana- 


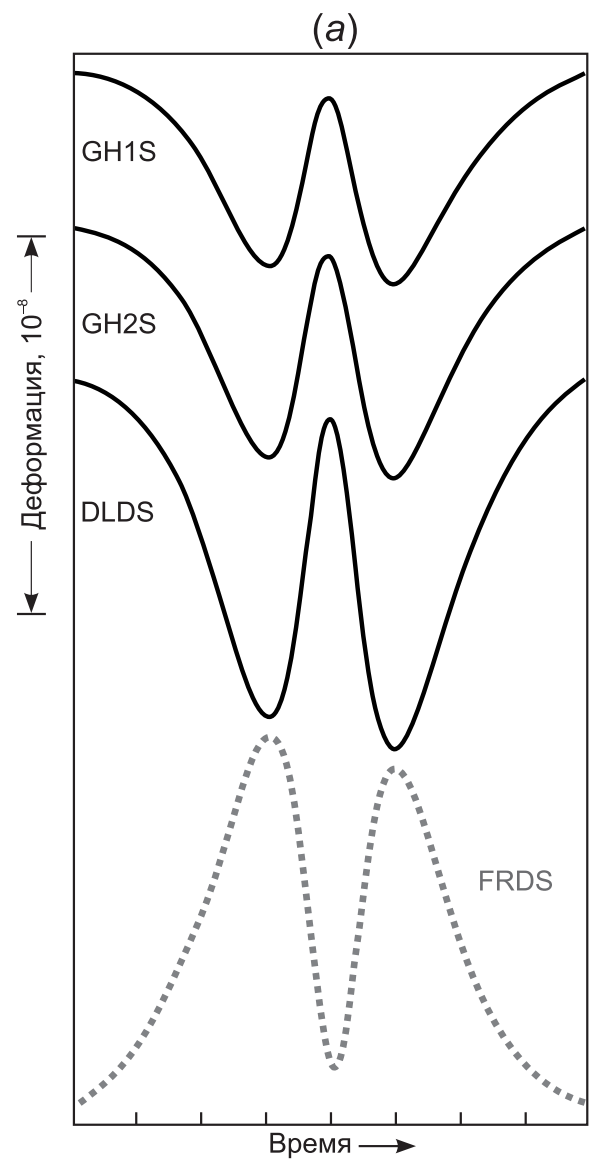

(б)

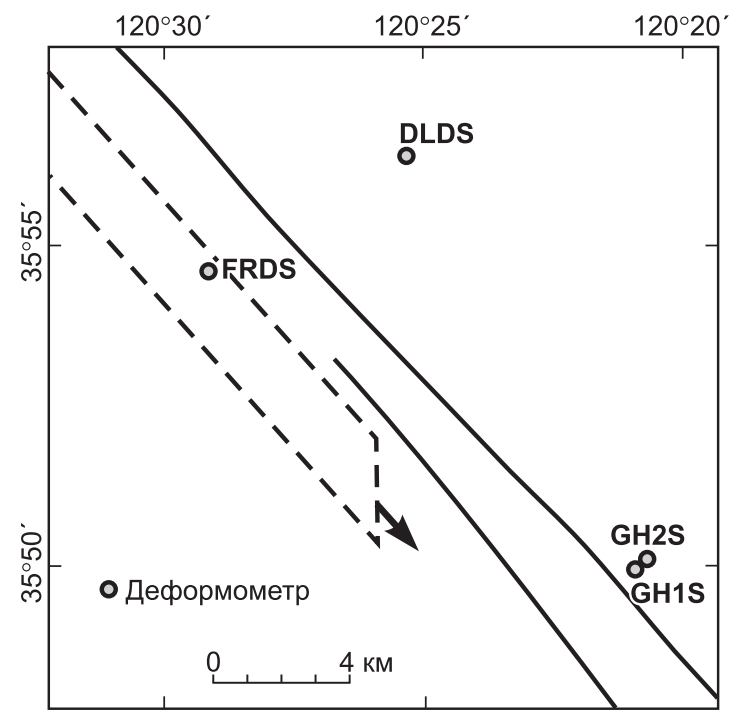

Рис. 12. Распространение «волн скольжения» в виде когерентных деформаций (a), зарегистрированных на поверхности разлома Сан-Андреас в Паркфилде (б) между 5 и 10 км трассы [Johnston, Linde, 2002].

Fig. 12. Propagation of 'slip waves' in the form of coherent deformation $(a)$ registered on the surface of the San Andreas fault in Parkfield (between the 5th and 10th $\mathrm{km}$ of the route) (б) [Johnston, Linde, 2002].

shvili, 1977], а также уединенные волны (кинки, солитоны) [Nikolaevskiy, 1998]. Медленные деформационные волны фиксируются как миграция деформации сдвига [Ishii et al., 1980] и как глобальные волны сжатия-растяжения [Lyuke et al., 1988; Saprygin et al., 1997]. Гидрогеологическими методами были зарегистрированы два вида волновых деформационных возмущений: перемещение фронта ступенчатого изменения напряжений [Nikolaevskiy, 1998] и миграция уединенных волн сжатия-растяжения [Kissin, 2008].

Длина деформационной волны зависит от скорости распространения и частоты колебаний источника волн. В общем случае порядок скорости деформационных волн определяется периодом волны $T$ и характерным размером $L$ блоков земной коры: $v \sim L T^{-1}$.

Скорость распространения деформационных волн, как уже было отмечено, равна $\left(10^{-4}-10^{-1}\right)$ м/с, т.е. меняется в довольно широком диапазоне. Что же касается частоты этих волн, то пока известны две группы - сравнительно низкочастотные и вы- сокочастотные. Первые имеют частоты порядка 10-10-10-9 Гц [Wang, Zhang, 2005; Sherman, 2007], вторые - 10-8-10-7 Гц [Nevsky, 1994; Saprygin et al., 1997]. Длина низкочастотных деформационных волн составляет несколько сотен или даже первые тысячи километров, высокочастотных - несколько десятков километров. Так, например, для частоты 10-8 Гц длина волны составляет 60-70 км.

Еще одно свойство - скорость волн миграции землетрясений является функцией их магнитуды. Скорость волн миграции тем больше, чем меньше магнитуды рассматриваемых в мигрирующей цепочке землетрясений [Nersesov et al., 1990; Vikulin et al., 2011, 2012].

\section{5. ТИПЫ ГЕОСТРУКТУР, ГЕНЕРИРУЮЩИЕ ДЕФОРМАЦИОННЫЕ ВОЛНЫ}

Из опубликованных результатов следует, что наиболее вероятными типами геоструктур, генерирующих деформационные волны, являются зоны 


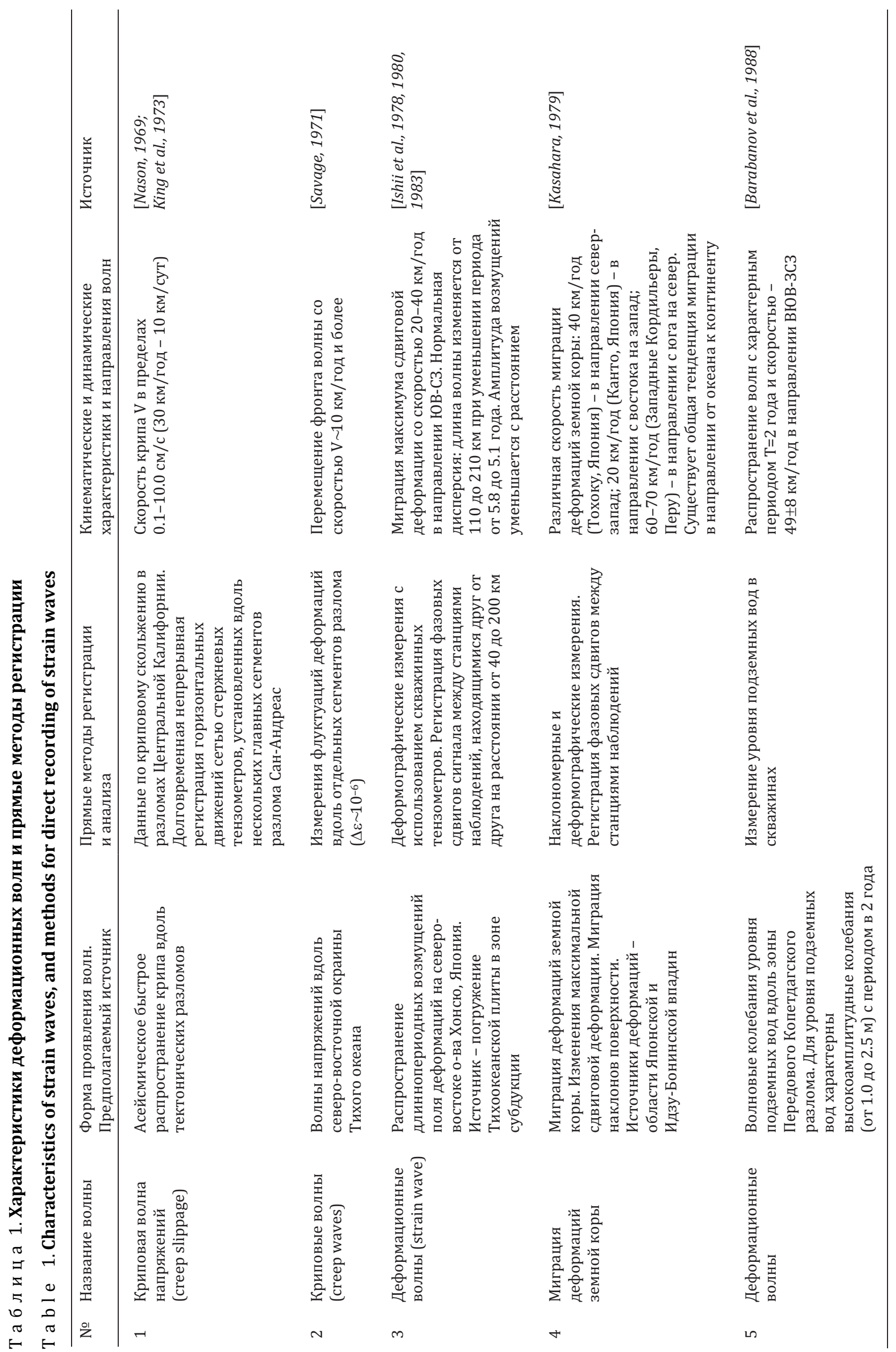




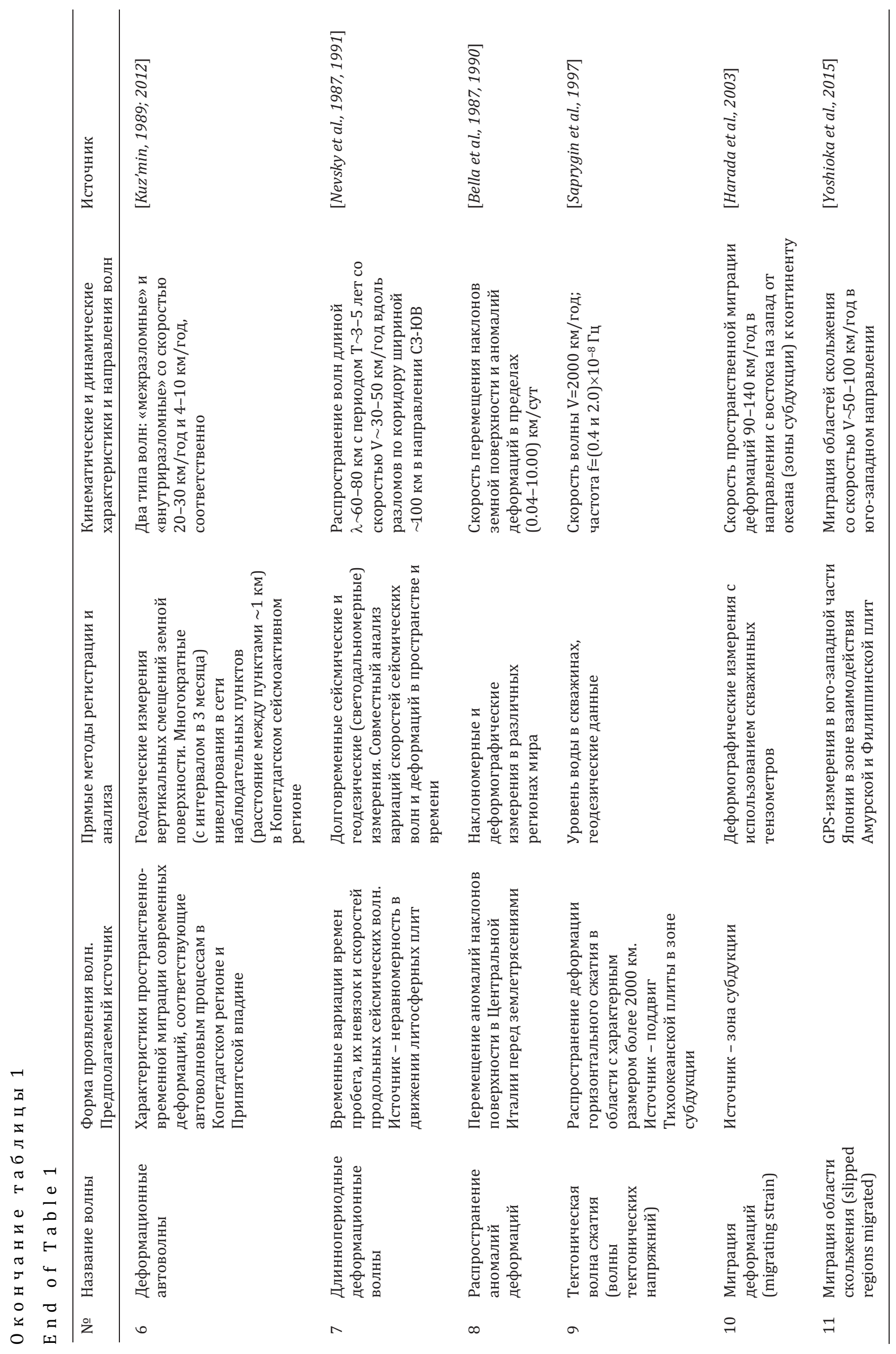




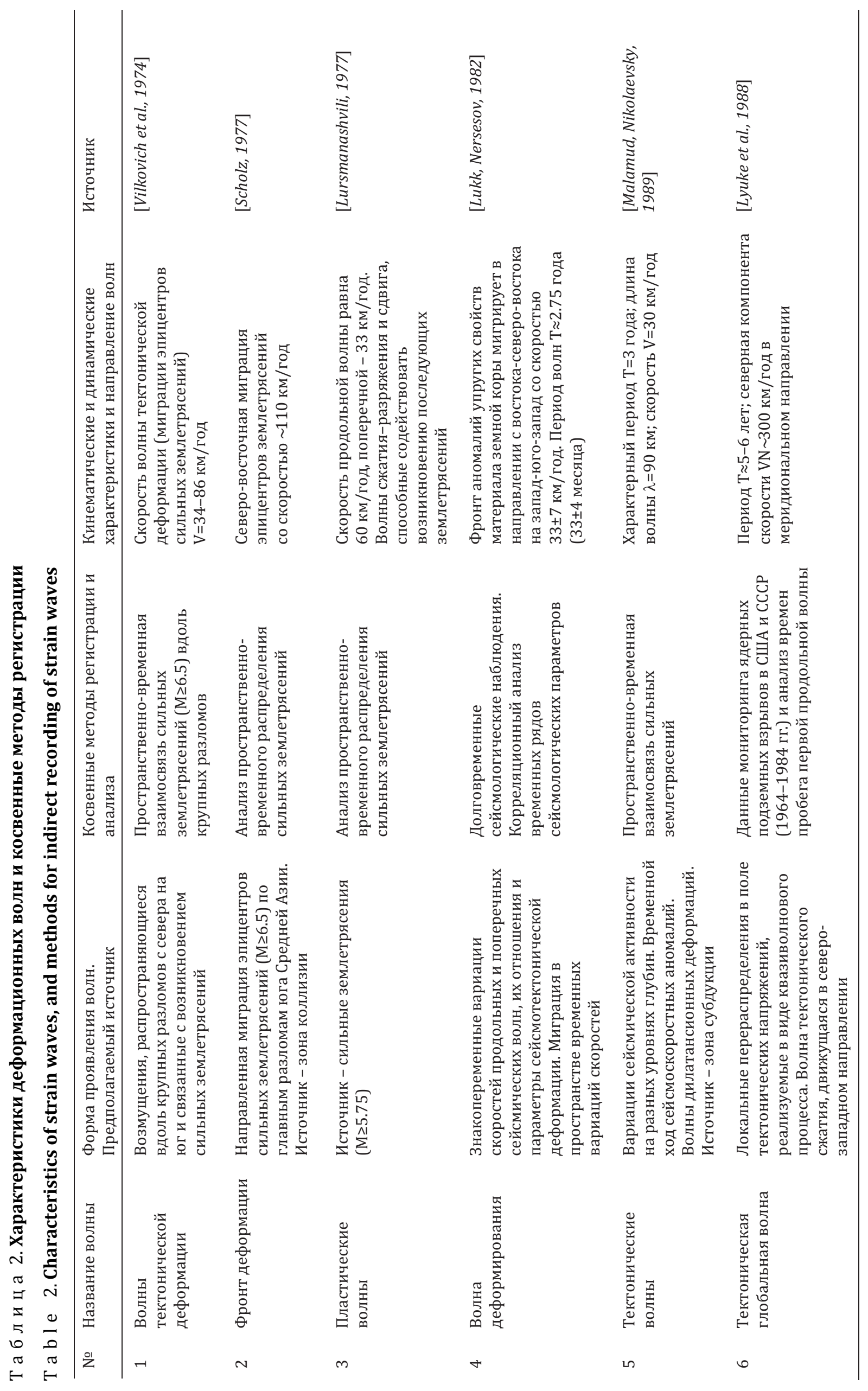




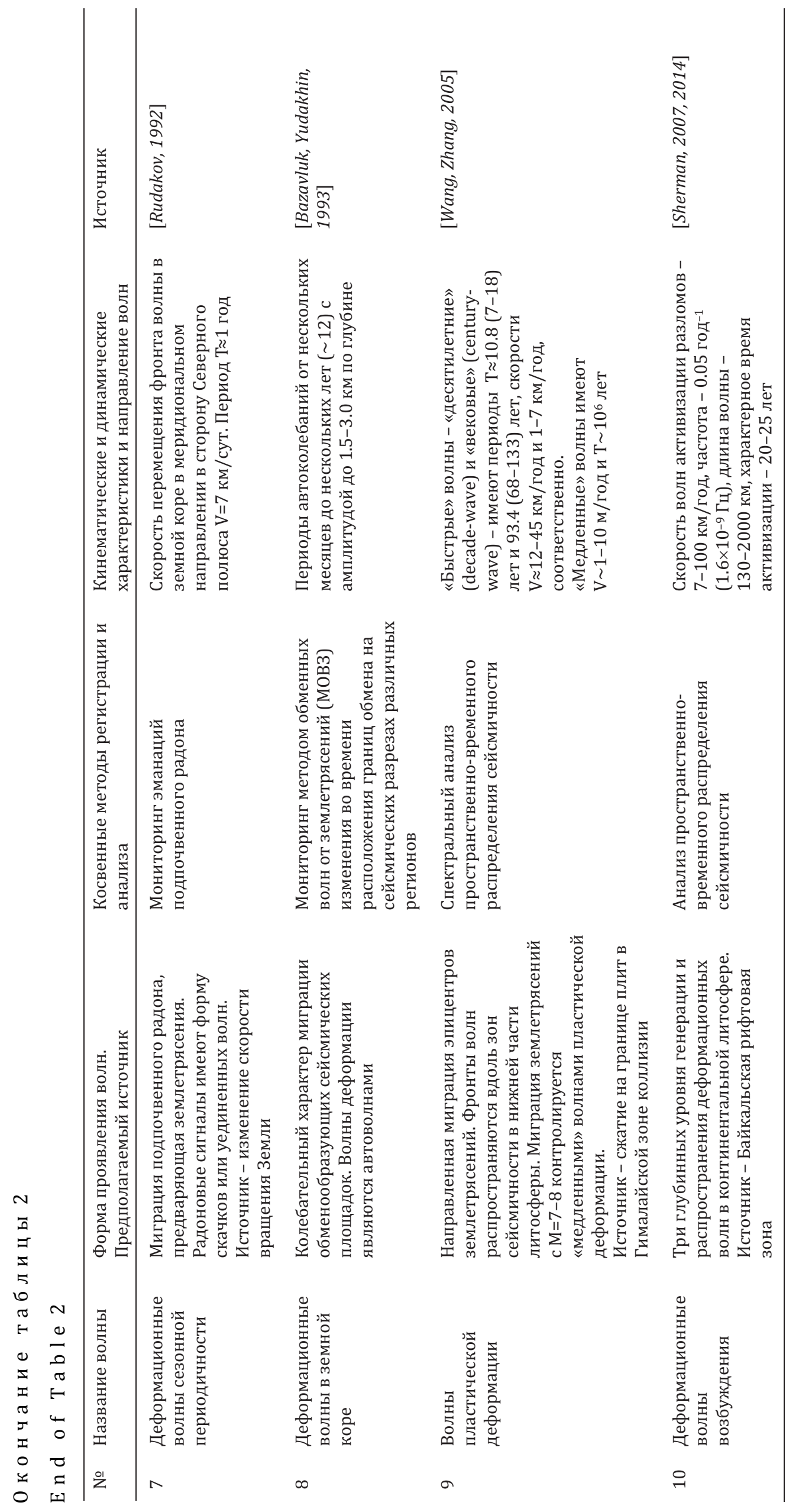


субдукции, зоны коллизии, зоны активного рифтогенеза и зоны трансформных разломов. Эти интенсивные источники различной тектонической природы имеют одно общее свойство - они являются зонами взаимодействия геоблоков и литосферных плит. И как уже неоднократно отмечалось, в лабораторных опытах генерирование медленных деформационных волн происходит также на контакте блоков горных пород.

Очень важным обстоятельством следует считать определение направления миграции сдвиговой деформации от океана к побережью. Эта общая тенденция впервые выявлена в области Японской островной дуги, где миграция имеет направление с востока на запад, и на противоположном Тихоокеанском побережье - в Западных Кордильерах, где деформации перемещались с юга на север [Kasaha$r a, 1979]$. Имеются также и другие, более поздние, свидетельства миграции деформаций, направленной из зон субдукции в сторону континента. Так, например, зафиксирована медленная миграция максимума вертикальных деформаций (вертикальных смещений) земной коры со скоростью около 10 км/год в зонах субдукции вблизи округа Тохоку (Северо-Восточная Япония) и полуострова Идзу (Центральная Япония), где Тихоокеанская и Филиппинская плиты погружаются под Евразийскую плиту [Miura et al., 1989]. Все эти данные привели к предположению, что одним из возможных источников деформационных волн являются зоны субдукции - зоны погружения океанических плит под континентальные плиты.

Более того, исследования динамики сейсмичности вдоль северной границы Амурской плиты показали, что здесь миграция эпицентров слабых землетрясений $(2 \leq \mathrm{M} \leq 4)$ инициируется перемещением фронта деформационной волны с востока на запад со средней скоростью 2.7 км/сут. Эта волна модулируется медленным волновым деформационным процессом со скоростью порядка 10-20 км/год, который зарождается в Японско-Курило-Камчатской зоне субдукции [Bykov, Trofimenko, 2016].

В нескольких тихоокеанских зонах субдукции выявлена миграция очагов землетрясений со скоростью 65-260 км/год вдоль погружающихся плит в направлении к земной поверхности [Molchanov, Uyeda, 2009; Molchanov, 2011] и со скоростью 90130 км/год в противоположном направлении вглубь Земли [Molchanov, 2011]. Прямыми трехкомпонентными деформографическими измерениями установлено [Harada et al., 2003], что в зоне субдукции генерируются деформации, распространяющиеся как вдоль, так и поперек погружающейся плиты.

Проявление сейсмичности на юге Средней Азии объясняется возбуждением волн деформации при колебательном режиме коллизии Евразийской и Индийской литосферных плит в зоне сочленения Памира и Тянь-Шаня [Nersesov et al., 1990]. Источником «быстрых» и «медленных» волн пластической деформации, инициирующих землетрясения в Центральной и Восточной Азии, является сжатие на границе Индостанской и Евразийской литосферных плит в Гималайской зоне коллизии [Wang, Zhang, 2005]. «Быстрые» волны - «десятилетние» (decade-wave) и «вековые» (century-wave) имеют периоды 7-18 и 68-133 лет, а скорости 12-45 и 1-7 км/год, соответственно. «Медленные» волны с периодом $10^{6}$ лет контролируют миграцию землетрясений с магнитудой $\mathrm{M} \geq 7.0$.

В Байкальской рифтовой зоне выделены основные группы деформационных волн, вызывающие современную сейсмическую активизацию разломов Центральной Азии. Величина скорости этих волн меняется от 7 до 95 км/год, а длина - от 130 до 2000 км [Sherman, Gorbunova, 2008; Gorbunova, Sherman, 2012].

Вращение блоков и микроплит в зонах интенсивного растяжения земной коры (литосферы) также может служить источником деформационных волн. Многими исследователями зафиксированы вращательные движения блоков геосреды, возникающие вследствие тектонических процессов или землетрясений, поэтому одним из основных физических механизмов генерации деформационных волн считается вращательное движение блоков в разломных зонах [Nikolaevsky, 1996].

Вдоль трансформных разломов на границах литосферных плит в Южной Калифорнии и Копетдагском регионе [Nevsky et al., 1987] установлено распространение медленных волн тектонических деформаций со скоростью 40-50 км/год, причем их перемещение происходит по узкому «коридору» шириной порядка 100 км [Nevsky et al., 1991]. Выдвинуто также предположение, что изменения сейсмической активности вдоль границы Тихоокеанской и Североамериканской плит в зоне трансформного разлома Сан-Андреас (Калифорния) связаны с медленно бегущими волнами деформации ("slowly traveling strain waves") [Press, Allen, 1995].

Сильным межплитным землетрясениям предшествует фаза увеличения сейсмической активности. В процессе подготовки землетрясений с $\mathrm{M} \geq 7.0$ наблюдается миграция более слабых толчков к эпицентру основного удара. Скорости миграции «фоновых» землетрясений составляют от 4 до 250 км/год [Pustovitenko, Porechnova, 2008; Novopashnina, San'kov, 2015]. Миграция толчков к зоне предстоящего сильного землетрясения, известная как «явление стягивания», фиксируется в широком диапазоне магнитуд независимо от сейсмотектоники регионов, а скорость миграции связана со 


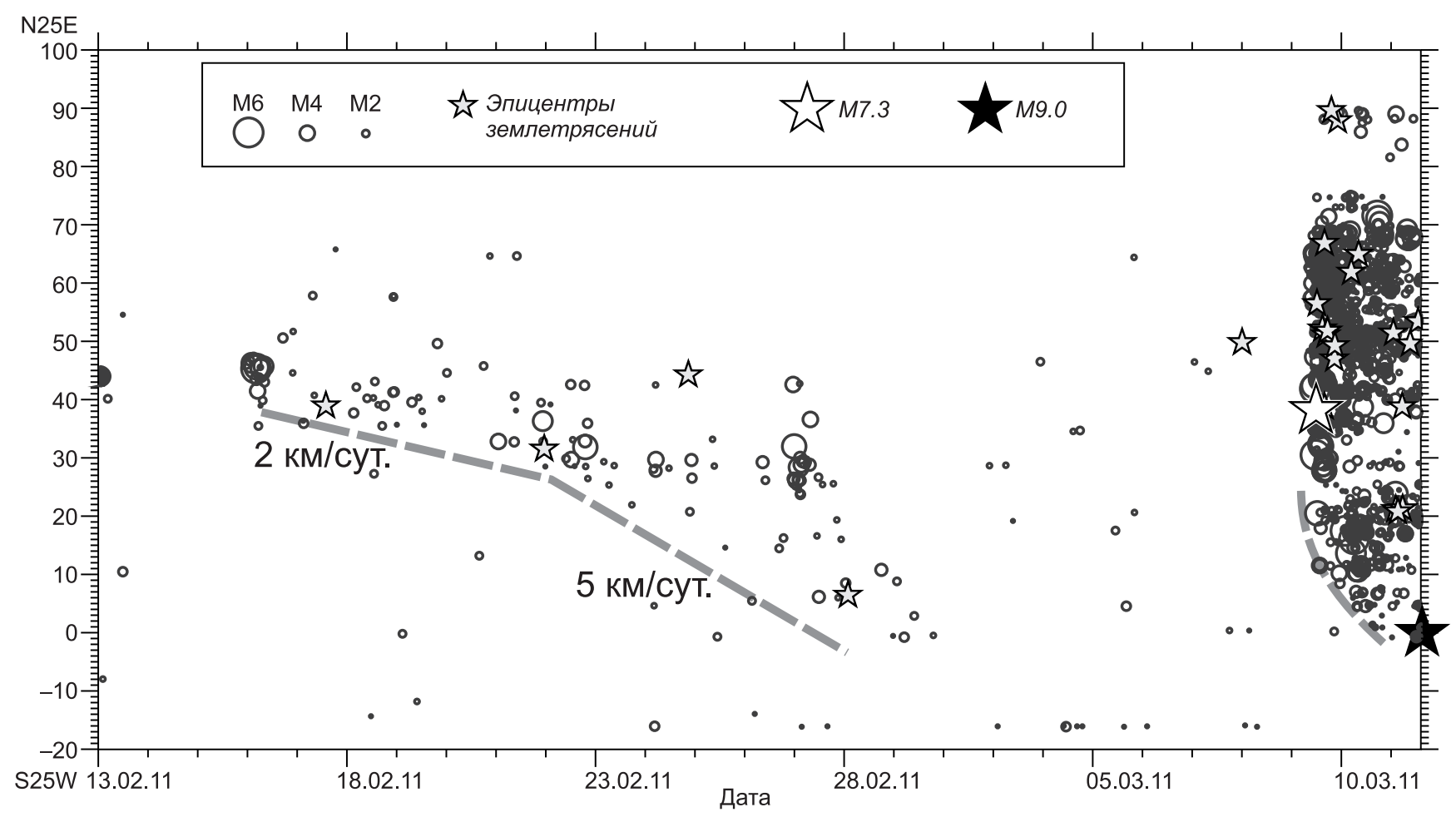

Рис. 13. Миграция землетрясений к эпицентру основного толчка землетрясения Тохоку [Kato et al., 2012].

Fig. 13. Migration of earthquakes toward the epicenter of the main shock of the Tohoku earthquake [Kato et al., 2012].

скоростью межплитных смещений [Novopashnina, San'kov, 2015].

В ходе ретроспективного анализа сильнейшего землетрясения Тохоку (11.03.2011 г., $\left.M_{\mathrm{w}}=9.0\right)$ идентифицированы две последовательности форшоков, мигрирующих со скоростью 2-5 и 10 км/сут вдоль оси океанического желоба к эпицентру (рис. 13). Медленное скольжение распространялось в пределах выделенной зоны миграции слабых землетрясений вдоль поверхности Тихоокеанской литосферной плиты к месту главного толчка [Kato et al., 2012]. Возможный физический механизм миграции форшоков - медленное скольжение по поверхности плит, схожее со скольжением на контакте блоков горных пород в лабораторных экспериментах stickslip.

\section{6. СОВРЕМЕННОЕ СОСТОЯНИЕ И ПЕРСПЕКТИВЫ РАЗВИТИЯ КОНЦЕПЦИИ ДЕФОРМАЦИОННЫХ ВОЛН ЗЕМЛИ}

В последние годы на качественно новом уровне активизировались исследования направленной миграции землетрясений - первоосновы концепции деформационных волн Земли [Di Giovambattista, Tyupkin, 2001; Pustovitenko, Porechnova, 2008; Sherman, 2007, 2013; Sherman, Gorbunova, 2008; Levina, Ruzhich, 2015; Vikulin et al., 2011, 2012; Liu et al., 2011;
Molchanov, Uyeda, 2009; Stepashko, 2013; Novopashina, San'kov, 2015; Ruzhich et al., 2016; Žalohar, 2018; Bykov, Trofimenko, 2016; Trofimenko et al., 2017]. Это связано, в первую очередь, с созданием уникальных баз данных, с разработкой новых методик исследования сейсмического процесса в планетарном масштабе и с применением современных информационно-вычислительных технологий для обработки и анализа огромных объемов исходной информации. В совокупности все это дает возможность получать новые количественные оценки параметров миграции землетрясений для построения волновых моделей сейсмотектонического режима Земли и изучать «тонкую структуру» и особенности распределения скоростей миграции сейсмической активности разных энергетических уровней.

Физическая основа концепции деформационных волн Земли состоит в фундаментальном свойстве геосреды - блочности и слоистости ее структуры. Именно на контактах твердых тел, границах раздела блоков и плит при их взаимном смещении происходит генерирование деформационных волн различного типа и масштаба [Bykov, 2008]. Характер перемещений на больших пространственных и временных масштабах при медленных деформациях горных масс определяется свойствами межблоковых контактов, а не материала блоков. По мнению С.В. Гольдина, медленные деформационные 
волны - это специфический механизм передачи энергии в блоковых средах [Goldin, 2002].

Впервые представления о блоковой структуре земной коры были сформированы в результате геодезических наблюдений и опубликованы в 1920-1930 гг. японскими учеными [Bilham, Beavan, 1979]. Было также установлено, что земная кора и литосфера представляют собой совокупность блоков и плит, размеры $L$ которых образуют дискретный иерархический ряд: $L=70,120,500,1200,3200$ км [Sadovsky et al., 1987].

Определены типы геоструктур, порождающих деформационные волны, и глубинные уровни (слои литосферы) распространения этих волн. С позиций двухъярусной тектоники плит [Lobkovsky, 1988] должны существовать два масштаба распространения тектонических волн на континентах: коровый и литосферный. При этом предполагается, что миграция сейсмической активности связана с коровым масштабом, так как именно в континентальной земной коре сосредоточена большая часть очагов землетрясений. По мере накопления новых данных С.И. Шерманом были выделены уже три глубинных уровня (масштаба) деформационных волн, охватывающих всю литосферу, верхний хрупкий слой литосферы и земную кору [Sherman, 2014]. Глобальные литосферные волны следуют из модели Эльзассера и его последователей. Разломно-блоковая структура верхнего упругого слоя литосферы и земной коры генерирует волны различных частот и скоростей в зависимости от размера блоков, составляющих эти слоиуровни [Sherman, 2013].

Количественно деформационные волновые процессы можно условно разделить на две группы: глобальные тектонические волны со скоростью 1100 км/год и деформационные волны в разломах со скоростью 1-10 км/сут, причем из моделей [Bott, Dean, 1973; Savage, 1971] следует, что при скорости деформационных волн порядка 100 км/год и более будут преобладать упругие взаимодействия соседних сегментов в зоне разлома, тогда как при меньших скоростях вязкоупругие свойства нижней коры и верхней мантии играют главную роль в медленном перемещении фронта деформации, например после сильнейших землетрясений [Sanders, 1993].

В различных регионах мира зафиксирована быстрая миграция сейсмической активности со скоростью 1-10 км/сут [Barabanov et al., 1994; Trofimenko et al., 2017]. Деформационные волны вдоль разломов земной коры проявляются в миграции аномалий геохимических и геофизических полей с такой же скоростью [Nikolaevskiy, 1998]. Скорость перемещения асейсмического крипа вдоль разлома Сан-Андреас в Центральной Калифорнии составляет порядка 10 км/сут [Nason, 1969; King et al., 1973]. Миграция медленного скольжения и эпизодиче- ского тремора в зонах субдукции и трансформных разломов происходит также со скоростью около 1-10 км/сут [Brudzinski, Allen, 2007; Beroza, Ide, 2011].

Имеются данные о миграции аномалий полей силы тяжести и магнитных полей со скоростью от 200 до 1200 км/год (0.7-4.0 км/сут), которые совпадают по времени проявления и по направлению перемещения [Bykov, Trofimenko, 2017]. Удивительно хорошее совпадение скоростей миграции указанных аномалий и их корреляция по скорости с миграцией сейсмической активности (2.7 км/сут) [Trofimenko et al., 2017] могут означать движение единого внутреннего источника возмущений напряженного состояния земной коры, инициирующего тектономагнитные, гравитационные и сейсмические эффекты. Этим источником может быть миграция деформаций земной коры в виде медленных волн.

Совпадение скорости перемещения аномалий геофизических полей со скоростью миграции слабых землетрясений, скоростью крипа, скоростью миграции деформаций, скоростью миграции тремора и медленного скольжения (ETS) - фундаментальный результат. Именно здесь в физике землетрясений можно ожидать основной прорыв.

Еще одним примером односторонне направленного перемещения природных аномалий является миграция сейсмической и вулканической активности. В 1976 г. французский исследователь К. Бло отмечал, что землетрясения и извержения вулканов в зоне субдукции «выстраиваются» в цепочку событий, скорость «включения» которых составляет около 300 км/год ( 1 км/сут). При этом он подчеркивал, что вулканическая активность на окраинах континентов - это результат, в том числе, «тектонического процесса» - переноса деформаций вдоль погружающейся литосферы, проявлением которого являются землетрясения [Blot, 1981].

A.В. Викулиным с коллегами [Vikulin et al., 2011, 2012] установлена пространственная корреляция миграции сейсмической и вулканической активности в пределах наиболее тектонически активных регионов Земли: окраины Тихого океана, Альпийско-Гималайского пояса, Срединно-Атлантического хребта. Корреляция эксплозии грязевых вулканов и землетрясений и перемещения деформационного фронта на о-ве Сахалин отмечена С.М. Сапрыгиным [Saprygin, 2013]. Корреляция во времени и пространстве извержений вулканов и сильнейших землетрясений $(\mathrm{M} \geq 8)$ обсуждалась в работе [Yamashina, 1989].

Таким образом, первые догадки о пространственной корреляции миграции деформаций с сейсмической и вулканической активностью [Kasahara, 1973] были подтверждены многочисленными 
исследованиями и сменились уверенностью, что сейсмичность и извержения вулканов управляются неким внутренним волновым процессом и являются его отражением на земной поверхности.

Несмотря на значительные успехи в теоретических и экспериментальных исследованиях, современное состояние проблемы генерации и детектирования деформационных волн Земли остается пока сложным.

Самый главный вопрос - это вопрос о физических механизмах генерирования медленных деформационных волн. Являются ли волны следствием колебательных (вращательных) движений разномасштабных блоков земной коры (литосферных плит) или волны возбуждаются при неустойчивом скольжении на контакте блоков (плит)?

Задачами первостепенной значимости можно считать: 1) выявление источников энергии деформационных волн; 2) выяснение причин цикличности появления уединенных волн деформации; 3) детальное исследование зависимости скорости медленных деформационных волн от структуры и физико-механических свойств геосреды.

Основная трудность выяснения доминирующего механизма генерирования и распространения деформационных волн состоит в том, что наблюдению доступен лишь интегральный эффект многих факторов различной природы, физическая суть которых не всегда ясна.

\section{7. ЗАКЛЮЧЕНИЕ}

В течение последних пятидесяти лет учеными разных стран в различных регионах Земли прямыми методами обнаружена миграция коровой деформации и выявлен ее волновой характер, а следовательно, доказана реальность существования деформационных волн Земли.

Интерес к медленным волновым движениям (тектоническим и деформационным волнам) в блоковых структурах земной коры и литосферы неизменно возрастает. По мнению многих исследователей, деформационные волны поддерживают равновесие между естественными процессами в земной коре и проявляются в изменениях не только деформационного, но и других геофизических полей.

Цель дальнейших исследований в этой области современной геодинамики - поиск и накопление новых фактов, признаков и проявлений медленных волновых деформационных процессов, выделение пространственно-временных тенденций в картине миграции очагов землетрясений и аномалий геофизических полей.

Основные задачи заключаются в разработке особого типа детекторов деформационных волн Земли, которые могли бы эффективно регистрировать эти волны, в построении адекватных моделей волновых геодинамических процессов и математическом моделировании передачи тектонических напряжений и эффектов, связанных с миграцией деформаций в геологической среде.

Трудность исследования деформационных волн Земли состоит, прежде всего, в неоднозначности интерпретации наблюдаемых величин. В большинстве случаев мы видим только «следы» этих волн. В 1982 г. сотрудники Института физики Земли АН СССР при обработке и интерпретации данных инструментальных сейсмических наблюдений нашли такие «следы» (периодические (5-7 лет) изменения скоростей сейсмических сигналов, их амплитуд и времен нарастания) и тем самым совершили косвенное открытие глобальных тектонических волн [Gamburtseva et al., 1982]. Нужно научиться правильно понимать результаты сейсмических, геодезических, геохимических, геоэлектрических и других измерений. Ведь из истории науки хорошо известно, что никакое наблюдение не может быть свободным от теории [Shapere, 1982], а любая интерпретация в значительной степени определяется принятой теоретической концепцией.

Можно без преувеличения отметить, что в перспективе исследования деформационных волн могут привести к кардинальным изменениям существующих представлений о сейсмическом процессе и взаимодействии разломов, стать ключом к пониманию механизма обмена энергией между геофизическими полями и верхними оболочками Земли, к выявлению новых прогностических признаков сейсмической опасности.

\section{8. БЛАГОДАРНОСТИ}

Исследование выполнено в рамках государственного задания Института тектоники и геофизики им. Ю.А. Косыгина ДВО РАН и при частичном финансировании РФФИ (проект № 16-05-00097).

\section{9. ЛИTЕРАTУPA / REFERENCES}

Aero E.L., Bulygin A.N., Pavlov Y.V., 2009. Solutions of the three-dimensional sine-Gordon equation. Theoretical and Mathematical Physics 158 (3), 313-319. https://doi.org/10.1007/s11232-009-0025-3. 
Albarello D., Bonafede M., 1990. Stress diffusion across laterally heterogeneous plates. Tectonophysics 179 (1-2), 121-130. https://doi.org/10.1016/0040-1951(90)90361-B.

Anderson D.L., 1975. Accelerated plate tectonics. Science 187 (4181), 1077-1079. https://doi.org/10.1126/science. 187.4181.1077.

Androsov I.V., Zhadin V.V., Potashnikov I.A., 1989. Spatial-temporal structure of earthquake migration and seismic belts. Doklady AN SSSR 306 (6), 1339-1342 (in Russian) [Андросов И.В., Жадин В.В., Поташников И.А. Пространственно-временная структура миграции землетрясений и сейсмические пояса // Доклады АН СССР. 1989. T. 306. № 6. C. 1339-1342].

Asada T. (Ed.), 1984. Earthquake Forecasting Methods. Their Application in Japan. Nedra, Moscow, 312 p. (in Russian) [Методы прогноза землетрясений. Их применение в Японии / Под ред. Т. Асада. М.: Недра, 1984. 312 с.].

Barabanov V.L, Grinevsky A.O., Belikov V.M., Ishankuliev G.A., 1994. On the migration of crustal earthquakes. In: A.V. Nikolaev (Ed.), Dynamic processes in geophysical medium. Nauka, Moscow, p. 149-167 (in Russian) [Барабанов В.Л., Гриневский А.О., Беликов В.М., Ишанкулиев Г.А. О миграции коровых землетрясений // Динамические процессы в геофизической среде / Ред. А.В. Николаев. М.: Наука, 1994. С. 149-167].

Barabanov V.L., Grinevsky A.O., Kissin I.G., Milkis M.R., 1988. Manifestations of strain waves in the hydrogeological and seismic regimes of the zone of the Frontal Kopetdag fault. Izvestiya AN SSSR, Seriya Fizika Zemli (5), 21-31 (in Russian) [Барабанов В.Л., Гриневский А.О., Киссин И.Г., Милькис М.Р. Проявления деформационных волн в гидрогеологическом и сейсмическом режимах зоны Передового Копетдагского разлома // Известия АН СCCP, серия Физика Земли. 1988. № 5. С. 21-31].

Baranov B.V., Lobkovsky L.I., 1980. Shallow-focus seismicity in the rear area of the Kuril Island arc and its relation to the Zavaritsky-Benioff zone. Doklady AN SSSR 255 (1), 67-71 (in Russian) [Баранов Б.В., Лобковский Л.И. Мелкофокусная сейсмичность в тылу Курильской островной дуги и ее связь с зоной Заварицкого-Беньофа // Доклады АН СССР. 1980. Т. 255. № 1. С. 67-71].

Baranov B.V., Vikulin A.V., Lobkovsky L.I., 1989. Shallow-focus seismicity in the rear area of the Kuril-Kamchatka island arc and its relation to the strongest earthquakes in the under-thrust zone. Vulkanologiya i Seismologiya (6), 73-84 (in Russian) [Баранов Б.В., Викулин А.В., Лобковский Л.И. Мелкофокусная сейсмичность в тылу КурилоКамчатской островной дуги и ее связь с сильнейшими землетрясениями в зоне поддвига // Вулканология и сейсмология. 1989. № 6. С. 73-84].

Bazavluk T.A., Yudakhin F.N., 1993. Strain waves in the crust of the Tien Shan from seismological data. Doklady AN 329 (5), 565-570 (in Russian) [Базавлук Т.A., Юдахин Ф.Н. Деформационные волны в земной коре Тянь-Шаня по сейсмологическим данным // Доклады АН. 1993. Т. 329. № 5. С. 565-570].

Bazavluk T.A., Yudakhin F.N., 1998. Temporal variations of exchange-forming inhomogeneities in the Earth's crust, Tien Shan. Doklady Earth Sciences 362 (7), 987-989.

Bella F., Bella R., Biagi P.F., Della Monica G., Ermini A., Sgrigna V., 1987. Tilt measurements and seismicity in Central Italy over a period of approximately three years. Tectonophysics 139 (3-4), 333-338. https://doi.org/10.1016/ 0040-1951(87)90108-9.

Bella F., Biagi P.F., Caputo M., Della Monica G., Ermini A., Manjgaladze P., Sgrigna V., Zilpimian D., 1990. Very slowmoving crustal strain disturbances. Tectonophysics 179 (1-2), 131-139. https://doi.org/10.1016/0040-1951(90) 90362-C.

Beroza G.C., Ide S., 2011. Slow earthquakes and nonvolcanic tremor. Annual Review of Earth and Planetary Sciences 39, 271-296. https://doi.org/10.1146/annurev-earth-040809-152531.

Bilham R.G., Beavan R.J., 1979. Strains and tilts on crustal blocks. Tectonophysics 52 (1-4), 121-138. https://doi.org/ 10.1016/0040-1951(79)90216-6.

Bird P., 2003. An updated digital model of plate boundaries. Geochemistry, Geophysics, Geosystems 4 (3), 1027. https://doi.org/10.1029/2001GC000252.

Birger B.I., 1989. Propagation of stresses in the Earth's lithosphere. Izvestiya AN SSSR, Seriya Fizika Zemli (12), 3-18 (in Russian) [Биргер Б.И. Распространение напряжений в литосфере Земли // Известия АН СССР, серия Физика Земли. 1989. № 12. С. 3-18].

Blot C., 1981. Earthquakes at depth beneath volcanoes, forerunners of their activities. Application to White Island, New Zealand. Journal of Volcanology and Geothermal Research 9 (4), 277-291. https://doi.org/10.1016/03770273(81)90040-8.

Bormotov V.A., Bykov V.G., 1999. Seismological monitoring of the deformation process. Tikhookeanskaya Geologiya 18 (6), 17-25 (in Russian) [Бормотов В.А., Быков В.Г. Сейсмологический мониторинг деформационного процесса // Тихоокеанская геология. 1999. Т. 18. № 6. С. 17-25].

Bornyakov S.A., Panteleev I.A., Tarasova A.A., 2016. Dynamics of intrafault deformation waves: results of physical simulation. Doklady Earth Sciences 471 (2), 1316-1318. https://doi.org/10.1134/S1028334X16120175.

Bott M.H.P., Dean D.S., 1973. Stress diffusion from plate boundaries. Nature 243 (5406), 339-341. https://doi.org/ 10.1038/243339a0.

Brace W.F., Byerlee J.D., 1966. Stick-slip as a mechanism for earthquakes. Science 153 (3739), 990-992. https:// doi.org/10.1126/science.153.3739.990. 
Braun O.M., Kivshar Yu.S., 1998. Nonlinear dynamics of the Frenkel-Kontorova model. Physics Reports 306 (1-2), 1-108. https://doi.org/10.1016/S0370-1573(98)00029-5.

Braun O.M., Kivshar Yu.S., 2008. The Frenkel-Kontorova Model. Concepts, Methods, and Applications. Fizmatlit, Moscow, 536 p. (in Russian) [Браун O.M., Кившарь Ю.С. Модель Френкеля-Конторовой. Концепции, методы, приложения. М.: Физматлит, 2008. 536 с.].

Brudzinski M.R., Allen R.M., 2007. Segmentation in episodic tremor and slip all along Cascadia. Geology 35 (10), $907-$ 910. https://doi.org/10.1130/G23740A.1.

Bykov V.G., 1996. On the possibility of the formation of solitary seismic waves in granular geomaterials. Journal of Mining Science 32 (2), 105-108. https://doi.org/10.1007/BF02046679.

Bykov V.G., 2000. Nonlinear Wave Processes in Geological Medium. Dal'nauka, Vladivostok, 190 p. (in Russian) [Быков В.Г. Нелинейные волновые процессы в геологических средах. Владивосток: Дальнаука, 2000. 190 c.].

Bykov V.G., 2001. A model of unsteady-state slip motion on a fault in a rock sample. Izvestiya, Physics of the Solid Earth 37 (6), 484-488.

Bykov V.G., 2005. Strain waves in the Earth: theory, field data, and models. Geologiya i Geofizika (Russian Geology and Geophysics) 46 (11), 1158-1170.

Bykov V.G., 2008. Stick-slip and strain waves in the physics of earthquake rupture: experiments and models. Acta Geophysica 56 (2), 270-285. https://doi.org/10.2478/s11600-008-0002-5.

Bykov V.G., 2014. Sine-Gordon equation and its application to tectonic stress transfer. Journal of Seismology 18 (3), 497-510. https://doi.org/10.1007/s10950-014-9422-7.

Bykov V.G., 2015. Nonlinear waves and solitons in models of fault block geological media. Russian Geology and Geophysics 56 (5), 793-803. https://doi.org/10.1016/j.rgg.2015.04.010.

Bykov V.G., Trofimenko S.V., 2016. Slow strain waves in blocky geological media from GPS and seismological observations on the Amurian plate. Nonlinear Processes in Geophysics 23 (6), 467-475. https://doi.org/10.5194/npg-23467-2016.

Bykov V.G., Trofimenko S.V., 2017. Slow strain waves from seismological and geophysical observations. Geophysical Research Abstracts 19, EGU2017-2380. Available from: https://meetingorganizer.copernicus.org/EGU2017/ EGU2017-2380.pdf.

Caputo M., 1979. Which is the correct stress strain relation for the anelasticity of the Earth's interior? Geophysical Journal of the Royal Astronomical Society 59 (1), 227-230. https://doi.org/10.1111/j.1365-246X.1979.tb02563.x.

Di Giovambattista R., Tyupkin Y., 2001. Cyclic migration of weak earthquakes between Lunigiana earthquake of October 10, 1995 and Reggio Emilia earthquake of October 15, 1996 (Northern Italy). Journal of Seismology 5 (2), 147-156. https://doi.org/10.1023/A:1011497601121.

Dillon O.W., 1966. Waves in bars of mechanically unstable materials. Journal of Applied Mechanics 33 (2), $267-274$. https://doi.org/10.1115/1.3625037.

Dragoni M., Bonafede M., Boschi E., 1982. Stress relaxation in the earth and seismic activity. La Rivista del Nuovo Cimento 5 (2), 1-34. https://doi.org/10.1007/BF02740828.

Elsasser W.M., 1969. Convection and stress propagation in the upper mantle. In: S.K. Runcorn (Ed.), The application of modern physics to the Earth and planetary interiors. Wiley, New York, p. 223-246.

Elsasser W.M., 1971. Two-layer model of upper-mantle circulation. Journal of Geophysical Research 76 (20), 4744-4753. https://doi.org/10.1029/JB076i020p04744.

Firstov P.P., Makarov E.O., Glukhova I.P., 2017. Peculiarities of subsoil gas dynamics before the M 7.2 Zhupanovo earthquake of January 30, 2016, Kamchatka. Doklady Earth Sciences 472 (2), 196-199. https://doi.org/10.1134/S10283 $34 X 17020015$.

Frank F.C., 1973. Dislocation models for fault creep processes. Philosophical Transactions of the Royal Society of London A: Mathematical, Physical and Engineering Sciences 274 (1239), 351-354. https://doi.org/10.1098/rsta.1973. 0062.

Gamburtseva N.G., Lyuke E.I., Nikolaevsky V.N., Oreshin S.I., Pasechnik I.P., Peregontseva V.E., Rubinshtein Kh.D., 1982. Periodic variations in seismic wave parameters during scanning of the lithosphere by strong explosions. Doklady AN SSSR 266 (6), 1349-1353 (in Russian) [Гамбурцева Н.Г., Люкэ Е.И., Николаевский В.Н., Орешин С.И., Пасечник И.П., Перегонщева В.Е., Рубинштейн Х.Д. Периодические вариации параметров сейсмических волн при просвечивании литосферы мощными взрывами // Доклады АН СССР. 1982. Т. 266. № 6. С. 1349-1353].

Garagash I.A., 1996. Microdeformations in a prestressed discrete geophysical medium. Transactions (Doklady) of the Russian Academy of Sciences / Earth Science Sections 347 (2), 324-327.

Garagash I.A., Nikolaevsky V.N., 2009. Cosserat mechanics in Earth sciences. Computational Continuum Mechanics 2 (4), 44-66 (in Russian) [Гарагаш И.А., Николаевский В.Н. Механика Коссера для наук о Земле // Вычислительная механика сплошных сред. 2009. Т. 2. № 4. С. 44-66]. https://doi.org/10.7242/1999-6691/2009.2.4.31.

Gershenzon N.I., Bambakidis G., 2014. Model of deep nonvolcanic tremor part I: Ambient and triggered tremor. Bulletin of the Seismological Society of America 104 (4), 2073-2090. https://doi.org/10.1785/0120130234. 
Gershenzon N.I., Bambakidis G., 2015. Model of deep nonvolcanic tremor part II: Episodic tremor and slip. Bulletin of the Seismological Society of America 105 (2A), 816-830. https://doi.org/10.1785/0120140225.

Gershenzon N.I., Bambakidis G., Hauser E., Ghosh A., Greager K.C., 2011. Episodic tremors and slip in Cascadia in the framework of the Frenkel-Kontorova model. Geophysical Research Letters 38 (1), L01309. https://doi.org/ 10.1029/2010GL045225.

Gershenzon N.I., Bykov V.G., Bambakidis G., 2009. Strain waves, earthquakes, slow earthquakes, and afterslip in the framework of the Frenkel-Kontorova model. Physical Review E 79 (5), 056601. https://doi.org/10.1103/ PhysRevE.79.056601.

Goldin S.V., 2002. Destruction of the lithosphere and physical mesomechanics. Fizicheskaya Mezomekhanika 5 (5), 5-22 (in Russian) [Гольдин С.В. Деструкция литосферы и физическая мезомеханика // Физическая мезомеханика. 2002. Т. 5. № 5. С. 5-22].

Gorbunova E.A., Sherman S.I., 2012. Slow deformation waves in the lithosphere: registration, parameters, and geodynamic analysis (Central Asia). Russian Journal of Pacific Geology 6 (1), 13-20. https://doi.org/10.1134/S18197 1401201006X.

Harada M., Furuzawa T., Teraishi M., Ohya F., 2003. Temporal and spatial correlations of the strain field in tectonic active region, southern Kyusyu, Japan. Journal of Geodynamics 35 (4-5), 471-481. https://doi.org/10.1016/ S0264-3707(03)00008-5.

Ida Y., 1974. Slow-moving deformation pulses along tectonic faults. Physics of the Earth and Planetary Interiors 9 (4), 328-337. https://doi.org/10.1016/0031-9201(74)90060-0.

Isacks B., Oliver J., Sykes L.R., 1968. Seismology and the new global tectonics. Journal of Geophysical Research 73 (18), 5855-5899. https://doi.org/10.1029/JB073i018p05855.

Ishii H., Sato T., Tachibana K., Hashimoto K., Murakami E., Mishina M., Miura S., Sato K., Takagi A., 1983. Crustal strain, crustal stress and microearthquake activity in the northeastern Japan arc. Tectonophysics 97 (1-4), 217-230. https://doi.org/10.1016/0040-1951(83)90149-X.

Ishii H., Sato T., Takagi A., 1978. Characteristics of strain migration in the Northeastern Japanese Arc. (I) - Propagation characteristics. Science reports of the Tohoku University, Series 5, Geophysics 25 (2), 83-90.

Ishii H., Sato T., Takagi A., 1980. Characteristics of strain migration in the Northeastern Japanese Arc. (II) - Amplitude characteristics. Journal of the Geodetic Society of Japan 26 (1), 17-25.

Ito T., Hashimoto M., 2001. Migrating crustal deformation from GEONET observations. Eos, Transactions American Geophysical Union 82 (47), F265-F265. Abstract G31A-0122.

Johnston M.J.S., Linde AT., 2002. Implications of crustal strain during conventional, slow, and silent earthquakes. In: W.H.K. Lee, H. Kanamori, P.C. Jennings, C. Kisslinger (Eds.), International handbook of earthquake and engineering seismology, Part A. International Geophysical Series, vol. 81. Academic Press, Amsterdam, p. 589-605.

Kasahara K., 1973. Earthquake fault studies in Japan. Philosophical Transactions of the Royal Society of London A Mathematical, Physical and Engineering Sciences 274 (1239), 287-296. https://doi.org/10.1098/rsta.1973.0055.

Kasahara K., 1979. Migration of crustal deformation. Tectonophysics 52 (1-4), 329-341. https://doi.org/10.1016/ 0040-1951(79)90240-3.

Kato A., Obara K., Igarashi T., Tsuruoka H., Nakagawa S., Hirata N., 2012. Propagation of slow slip leading up to the 2011 Mw 9.0 Tohoku-Oki earthquake. Science 335 (6069), 705-708. https://doi.org/10.1126/science.1215141.

Kenig M.J., Dillon O.W., 1966. Shock waves produced by small stress increments in annealed aluminum. Journal of Applied Mechanics 33 (4), 907-916. https://doi.org/10.1115/1.3625201.

King C.-Y., Nason R.D., Tocher D., 1973. Kinematics of fault creep Philosophical Transactions of the Royal Society of London A: Mathematical, Physical and Engineering Sciences 274 (1239), 355-360. https://doi.org/10.1098/rsta. 1973.0063.

Kissin I.G., 2008. Hydrogeological effects of strain waves in the crust. Geofizicheskie Issledovaniya 9 (1), 43-52 (in Russian) [Киссин И.Г. Гидрогеологические эффекты деформационных волн в земной коре // Геофизические исследования. 2008. Т. 9. № 1. С. 43-52].

Kontorova T.A., Frenkel Ya.I., 1938. To the theory of plastic deformation and twinning. Journal of Experimental and Theoretical Physics 8 (1), 89-95 (in Russian) [Конторова T.A., Френкель Я.И. К теории пластической деформации и двойникования. I // Журнал экспериментальной и теоретической физики. 1938. Т. 8. № 1. С. 89-95].

Kreemer C., Blewitt G., Klein E.C., 2014. A geodetic plate motion and global strain rate model. Geochemistry, Geophysics, Geosystems 15 (10), 3849-3889. https://doi.org/10.1002/2014GC005407.

Kuz'min Y.O., 1989. Modern geodynamics of fault zones in sedimentary basins, and earthquake preparation processes. In: Earthquake Forecasting. No. 11. Donish, Moscow - Dushanbe, p. 52-60 (in Russian) [Кузьмин Ю.О. Современная геодинамика разломных зон осадочных бассейнов и процессы подготовки землетрясений // Прогноз землетрясений. № 11. Москва-Душанбе: Дониш, 1989. С. 52-60].

Kuz'min Y.O., 2012. Deformation autowaves in fault zones. Izvestiya, Physics of the Solid Earth 48 (1), 1-16. https://doi.org/10.1134/S1069351312010089.

Kuznetsov I.V., Keilis-Borok V.I., 1997. The interrelation of earthquakes of the Pacific seismic belt. Transactions (Doklady) of the Russian Academy of Sciences / Earth Science Sections 355 (6), 869-873. 
Landa P.S., 1997. Nonlinear Oscillations and Waves. Nauka, Fizmatlit, Moscow, 496 p. (in Russian) [Ланда П.С. Нелинейные колебания и волны. М.: Наука, Физматлит, 1997. 496 с.].

Lehner F.K., Li V.C., Rice J.R., 1981. Stress diffusion along rupturing plate boundaries. Journal of Geophysical Research: Solid Earth 86 (B7), 6155-6169. https://doi.org/10.1029/JB086iB07p06155.

Levina E.A., Ruzhich V.V., 2015. The seismicity migration study based on space-time diagrams. Geodynamics \& Tectonophysics 6 (2), 225-240. https://doi.org/10.5800/GT-2015-6-2-0178.

Liu H.P., Anderson D.L., Kanamori H., 1976. Velocity dispersion due to anelasticity; implications for seismology and mantle composition. Geophysical Journal of the Royal Astronomical Society 47 (1), 41-58. https://doi.org/10.1111/ j.1365-246X.1976.tb01261.x.

Liu M., Stein S., Wang H., 2011. 2000 years of migrating earthquakes in North China: how earthquakes in midcontinents differ from those at plate boundaries. Lithosphere 3 (2), 128-132. https://doi.org/10.1130/L129.1.

Lobkovsky L.I., 1988. Geodynamics of Spreading and Subduction Zones, and Two-Level Plate Tectonics. Nauka, Moscow, 294 p. (in Russian) [Лобковский Л.И. Геодинамика зон спрединга, субдукции и двухъярусная тектоника плит. М.: Наука, 1988. 294 с.].

Lowry A.R., 2006. Resonant slow fault slip in subduction zones forced by climatic load stress. Nature 442 (7104), 802-805. https://doi.org/10.1038/nature05055.

Lu D., 1980. Stress wave, motion of strain wave and slow earthquake. Scientia Sinica 23 (11), 1428-1434.

Lukk A.A., Nersesov I.L., 1982. Variations in time of different parameters of the seismotectonic process. Izvestiya AN SSSR, Seriya Fizika Zemli (3), 10-27 (in Russian) [Лукк А.А., Нерсесов И.Л. Вариации во времени различных параметров сейсмотектонического процесса // Известия АН СССР, серия Физика Земли. 1982. № 3. С. 10-27].

Lursmanashvili O.V., 1977. Temporal-spatial distribution of strong earthquakes in the Caucasus, and potential interrelation between earthquakes through plastic waves. Reports of the Academy of Sciences of the Georgian SSR 87 (3), 601-604 (in Russian) [Лурсманашвили О.В. Временно-пространственное распределение сильных землетрясений Кавказа и возможность взаимосвязи землетрясений через пластические волны // Сообщения Академии наук Грузинской ССР. 1977. Т. 87. № 3. С. 601-604].

Lyuke E.I., An V.A., Pasechnik I.P., 1988. Detection of the front of a tectonic global wave during seismic scanning of the Earth. Doklady AN SSSR 301 (3), 569-573 (in Russian) [Люкэ Е.И., Ан В.А., Пасечник И.П. Обнаружение фронта тектонической глобальной волны при сейсмическом просвечивании Земли // Доклады АН СССР. 1988. T. 301. № 3. С. 569-573].

Makarov P.V., 2007. Evolutionary nature of structure formation in lithospheric material: universal principle for fractality of solids. Russian Geology and Geophysics 48 (7), 558-574. https://doi.org/10.1016/j.rgg.2007.06.003.

Makarov P.V., Peryshkin A.Y., 2017. Slow motions as inelastic strain autowaves in ductile and brittle media. Physical Mesomechanics 20 (2), 209-221. https://doi.org/10.1134/S1029959917020114.

Malamud A.S., Nikolaevsky V.N., 1989. Earthquake Cycles and Tectonic Waves. Donish, Dushanbe, 142 p. (in Russian) [Маламуд A.C., Николаевский В.Н. Циклы землетрясений и тектонические волны. Душанбе: Дониш, 1989. 142 c.].

Malin P.E., Alvarez M.G., 1992. Stress diffusion along the San Andreas fault at Parkfield, California. Science 256 (5059), 1005-1007. https://doi.org/10.1126/science.256.5059.1005.

McLaughlin D.W., Scott A.C., 1978. Perturbation analysis of fluxon dynamics. Physical Review A 18 (4), 1652-1680. https://doi.org/10.1103/PhysRevA.18.1652.

McReynolds A.W., 1949. Plastic deformation waves in aluminum. Transactions of the American Institute of Mining and Metallurgical Engineers 185 (1), 32-45.

Melosh H.J., 1976. Nonlinear stress propagation in the Earth's upper mantle. Journal of Geophysical Research 81 (32), 5621-5632. https://doi.org/10.1029/JB081i032p05621.

Mikhailov D.N., Nikolaevskii V.N., 2000. Tectonic waves of the rotational type generating seismic signals. Izvestiya, Physics of the Solid Earth 36 (11), 895-902.

Milyukov V., Mironov A., Kravchuk V., Amoruso A., Crescentini L., 2013. Global deformations of the Eurasian plate and variations of the Earth rotation rate. Journal of Geodynamics 67, 97-105. https://doi.org/10.1016/j.jog.2012. 05.009.

Mitlin V.S., Nikolaevsky V.N., 1990. Nonlinear diffusion of tectonic stresses. Doklady AN SSSR 315 (5), 1093-1096 (in Russian) [Митлин В.C., Николаевский В.Н. Нелинейная диффузия тектонических напряжений // Доклады AH CСCP. 1990. T. 315. № 5. C. 1093-1096].

Miura S., Ishii H., Takagi A., 1989. Migration of vertical deformations and coupling of island arc plate and subducting plate. In: S.C. Cohen, P. Vanííek (Eds.), Slow deformation and transmission of stress in the Earth. Geophysical Monograph Series, vol. 49, p. 125-138. https://doi.org/10.1029/GM049p0125.

Mogi K., 1968. Migration of seismic activity. Bulletin of the Earthquake Research Institute 46, 53-74.

Molchanov O.A., 2011. Underlying mechanism of precursory activity from analysis of upward earthquake migration. Natural Hazards and Earth System Sciences 11 (1), 135-143. https://doi.org/10.5194/nhess-11-135-2011. 
Molchanov O.A., Uyeda S., 2009. Upward migration of earthquake hypocenters in Japan, Kurile-Kamchatka and Sunda subduction zones. Physics and Chemistry of the Earth, Parts A/B/C 34 (6-7), 423-430. https://doi.org/10.1016/ j.pce.2008.09.011.

Nason R.D., 1969. Preliminary instrumental measurements of fault creep slippage on the San Andreas fault, California. Earthquake Notes 40 (1), 7-10. https://doi.org/10.1785/gssrl.40.1.7.

Nersesov I.L., Lukk A.A., Zhuravlev V.I., Galaganov O.N., 1990. On propagation of strain waves in the crust of the southern regions of Central Asia. Izvestiya AN SSSR, Seriya Fizika Zemli (5), 102-112 (in Russian) [Нерсесов И.Л., Лукк А.А., Журавлев В.И., Галаганов О.Н. О распространении деформационных волн в земной коре юга Средней Азии // Известия АН СССР, серия Физика Земли. 1990. № 5. С. 102-112].

Nevsky M.V., 1994. Ultra-long-period strain waves at the boundaries of lithospheric plates. In: A.V. Nikolaev (Ed.) Dynamic processes in geophysical medium. Nauka, Moscow, p. 40-55 (in Russian) [Невский М.В. Сверхдлиннопериодные волны деформаций на границах литосферных плит // Динамические процессы в геофизической среде / Ред. А.В. Николаев. М.: Наука, 1994. С. 40-55].

Nevsky M.V., Artamonov A.M., Riznichenko O.Yu., 1991. Strain waves and seismicity energy. Doklady AN SSSR 318 (2), 316-320 (in Russian) [Невский М.В., Артамонов А.М., Ризниченко О.Ю. Волны деформации и энергетика сейсмичности // Доклады АН СССР. 1991. Т. 318. № 2. С. 316-320].

Nevsky M.V., Morozova L.A., Fyuz G.S., 1989. Long-period deformation waves. In: M.A. Sadovsky (Ed.), Discrete properties of geophysical medium. Nauka, Moscow, p. 18-33 (in Russian) [Невский М.В., Морозова Л.А., Фьюз Г.С. Длиннопериодные деформационные волны // Дискретные свойства геофизической среды / Ред. М.А. Садовский. М.: Наука, 1989. С. 18-33].

Nevsky M.V., Morozova L.A., Zhurba M.N., 1987. The effect of propagation of long-period deformation perturbations Doklady AN SSSR 296 (5), 1090-1093 (in Russian) [Невский М.В., Морозова Л.А., Журба М.Н. Эффект распространения длиннопериодных деформационных возмущений // Доклады АН СССР. 1987. Т. 296. № 5. C. 1090-1093].

Nielsen S., Taddeucci J., Vinciguerra S., 2010. Experimental observation of stick-slip instability fronts. Geophysical Journal International 180 (2), 697-702. https://doi.org/10.1111/j.1365-246X.2009.04444.x.

Nikolaevskiy V.N., 1998. Tectonic stress migration as nonlinear wave process along earth crust faults. In: T. Adachi, F. Oka, A. Yashima (Eds.), Proceedings of 4th International workshop on localization and bifurcation theory for soils and rocks (Gifu, Japan, 28 September - 2 October 1997). A.A. Balkema, Rotterdam, p. 137-142.

Nikolaevsky V.N., 1983. Mechanics of geomaterials and earthquakes. In: Science and technics results. Mechanics of deformed solid body. Vol. 15. VINITI, Moscow, p. 149-230 (in Russian) [Николаевский В.Н. Механика геоматериалов и землетрясения // Итоги науки и техники. Механика деформируемого твердого тела. Т. 15. М.: ВИНИТИ, 1983. С. 149-230].

Nikolaevsky V.N., 1995. Mathematical modeling of solitary deformation and seismic waves. Doklady AN 341 (3), 403-405 (in Russian) [Николаевский В.Н. Математическое моделирование уединенных деформационных и сейсмических волн // Доклады АН. 1995. Т. 341. № 3. С. 403-405].

Nikolaevsky V.N., 1996. Geomechanics and Fluid Dynamics. Nedra, Moscow, 447 p. (in Russian) [Николаевский В.Н. Геомеханика и флюидодинамика. М.: Недра, 1996. 447 с.].

Nikolaevsky V.N., Ramazanov T.K., 1985. Theory of fast tectonic waves. Applied Mathematics and Mechanics 49 (3), 462-469 (in Russian) [Николаевский В.Н., Рамазанов Т.К. Теория быстрых тектонических волн // Прикладная математика и механика. 1985. Т. 49. № 3. С. 462-469].

Nikolaevsky V.N., Ramazanov T.K., 1986. Generation and propagation of tectonic waves along deep faults. Izvestiya AN SSSR, Seriya Fizika Zemli (10), 3-13 (in Russian) [Николаевский В.Н., Рамазанов Т.К. Генерация и распространение тектонических волн вдоль глубинных разломов // Известия АН СССР, серия Физика Земли. 1986. № 10. C. 3-13].

Novopashnina A.V., San'kov V.A., 2015. Migration of seismic activity in strike-slip zones: A case study of the boundary between the North American and Pacific plates. Russian Journal of Pacific Geology 9 (2), 141-153. https://doi.org/ 10.1134/S1819714015020050.

Obara K., 2002. Nonvolcanic deep tremor associated with subduction in southwest Japan. Science 296 (5573), 1679-1681. https://doi.org/10.1126/science.1070378.

Ohnaka M., 2013. The Physics of Rock Failure and Earthquakes. Cambridge University Press, New York, $270 \mathrm{p}$.

Ouchi T., Goriki S., Ito K., 1985. On the space-time pattern formation of the earthquake strain field. Tectonophysics 113 (1-2), 31-48. https://doi.org/10.1016/0040-1951(85)90109-X.

Peyrard M., Kruskal M.D., 1984. Kink dynamics in the highly discrete sine-Gordon system. Physica D: Nonlinear Phenomena 14 (1), 88-102. https://doi.org/10.1016/0167-2789(84)90006-X.

Pollitz F.F., Bürgmann R., Romanowicz B., 1998. Viscosity of oceanic asthenosphere inferred from remote triggering of earthquakes. Science 280 (5367), 1245-1249. https://doi.org/10.1126/science.280.5367.1245.

Press F., Allen C., 1995. Patterns of seismic release in the southern California region. Journal of Geophysical Research: Solid Earth 100 (B4), 6421-6430. https://doi.org/10.1029/95JB00316.

Prokhorov A.M. (Ed.), 1983. Physical Encyclopedic Dictionary. Soviet Encyclopedia, Moscow, 928 p. (in Russian) [Физический энциклопедический словарь / Ред. А.М. Прохоров. М.: Советская энциклопедия, 1983. 928 с.]. 
Pustovitenko B.G., Porechnova E.I., 2008. On the processes of formation of focal zones of strong earthquakes. Geophysical Journal 30 (5), 73-90 (in Russian) [Пустовитенко Б.Г., Поречнова Е.И. О процессах формирования очаговых зон сильных землетрясений // Геофизический журнал. 2008. Т. 30. № 5. С. 73-90].

Reuveni Y., Kedar S., Moore A., Webb F., 2014. Analyzing slip events along the Cascadia margin using an improved subdaily GPS analysis strategy. Geophysical Journal International 198 (3), 1269-1278. https://doi.org/10.1093/ gji/ggu208.

Rice J.R., 1980. The mechanics of earthquake rupture. In: A.M. Dziewonski, E. Boschi (Eds.), Physics of the Earth's Interior. Italian Physical Society / North-Holland, Amsterdam, p. 555-649.

Richter E.F., 1958. Elementary Seismology. W.H. Freeman, San Francisco, 768 p.

Rudakov V.P., 1992. Mapping of geodeformation processes of seasonal (annual) periodicity in the dynamics of the subsoil radon field. Doklady AN 324 (3), 558-561 (in Russian) [Рудаков В.П. Отображение геодеформационных процессов сезонной (годовой) периодичности в динамике поля подпочвенного радона // Доклады $A H$. 1992. T. 324. № 3. C. 558-561].

Ruzhich V.V., Kocharyan G.G., Levina E.A., 2016. Estimated geodynamic impact from zones of collision and subduction on the seismotectonic regime in the Baikal rift. Geodynamics \& Tectonophysics 7 (3), 383-406 (in Russian) [Ружич В.В., Кочарян Г.Г., Левина Е.А. Оценка геодинамического влияния зон коллизии и субдукции на сейсмотектонический режим Байкальского рифта // Геодинамика и тектонофизика. 2016. Т. 7. № 3. C. 383-406]. https://doi.org/10.5800/GT-2016-7-3-0214.

Rydelek P.A., Sacks I.S., 1988. Asthenospheric viscosity inferred from correlated land-sea earthquakes in north-east Japan. Nature 336 (6196), 234-237. https://doi.org/10.1038/336234a0.

Rydelek P.A., Sacks I.S., 1990. Asthenospheric viscosity and stress diffusion: a mechanism to explain correlated earthquakes and surface deformations in NE Japan. Geophysical Journal International 100 (1), 39-58. https://doi.org/ 10.1111/j.1365-246X.1990.tb04566.X.

Sadovsky M.A., Bolkhovitinov L.G., Pisarenko V.F., 1987. Deformation of Geophysical Medium and Seismic Process. Nauka, Moscow, 100 p. (in Russian) [Садовский М.А., Болховитинов Л.Г., Писаренко В.Ф. Деформирование геофизической среды и сейсмический процесс. М.: Наука, 1987. 100 с.].

Sanders C.O., 1993. Interaction of the San Jacinto and San Andreas fault zones, Southern California: triggered earthquake migration and coupled recurrence intervals. Science 260 (5110), 973-976. https://doi.org/10.1126/ science.260.5110.973.

Saprygin S.M., 2013. To the problem of seismicity of the Sakhalin faults. Tikhookeanskaya Geologiya 32 (2), 73-77 (in Russian) [Сапрыгин С.M. К проблеме сейсмичности разломов Сахалина // Тихоокеанская геология. 2013. T. 32. № 2. C. 73-77].

Saprygin S.M., Vasilenko N.F., Soloviev V.N., 1997. Propagation of the wave of tectonic stresses through the Eurasian plate in 1978-1983. Geologiya i Geofizika (Russian Geology and Geophysics) 38 (3), 701-709.

Sato K., 1989. Numerical experiments on strain migration. Journal of the Geodetic Society of Japan 35 (1), 27-36 (in Japanese with English abstract).

Savage J.C., 1971. A theory of creep waves propagating along a transform fault. Journal of Geophysical Research 76 (8), 1954-1966. https://doi.org/10.1029/JB076i008p01954.

Scholz C., 1977. A physical interpretation of the Haicheng earthquake prediction. Nature 267 (5607), 121-124. https://doi.org/10.1038/267121a0.

Scholz C., Molnar P., Johnson T., 1972. Detailed studies of frictional sliding of granite and implications for the earthquake mechanism. Journal of Geophysical Research 77 (32), 6392-6406. https://doi.org/10.1029/ JB077i032p06392.

Schwartz S.Y., Rokosky J.M., 2007. Slow slip events and seismic tremor at Circum-Pacific subduction zones. Reviews of Geophysics 45 (3), RG3004. https://doi.org/10.1029/2006RG000208.

Scott A.C., 2007. The Nonlinear Universe. Chaos, Emergence, Life. Springer, Berlin-Heidelberg-New York, 365 p.

Shapere D., 1982. The concept of observation in science and philosophy. Philosophy of Science 49 (4), 485-525. https://doi.org/10.1086/289075.

Shelly D.R., Beroza G.C., Ide S., 2007. Non-volcanic tremor and low-frequency earthquake swarms. Nature 446 (7133), 305-307. https://doi.org/10.1038/nature05666.

Sherman S.I., 2007. New data on regularities of fault activation in the Baikal rift system and the adjacent territory. Doklady Earth Sciences 415 (1), 794-798. https://doi.org/10.1134/S1028334X07050303.

Sherman S.I., 2013. Deformation waves as a trigger mechanism of seismic activity in seismic zones of the continental lithosphere. Geodynamics \& Tectonophysics 4 (2), 83-117 (in Russian) [Шерман С.И. Деформационные волны как триггерный механизм сейсмической активности в сейсмических зонах континентальной литосферы // Геодинамика и тектонофизика. 2013. Т. 4. № 2. C. 83-117]. https://doi.org/10.5800/GT-2013-4-2-0093.

Sherman S.I., 2014. Seismic Process and the Forecast of Earthquakes: Tectonophysical Conception. Academic Publishing House "Geo", Novosibirsk, 359 p. (in Russian) [Шерман С.И. Сейсмический процесс и прогноз землетрясений: тектонофизическая концепция. Новосибирск: Академическое издательство «Гео», 2014. 359 c.]. 
Sherman S.I., Gorbunova E.A., 2008. Wave nature of activation of faults in Central Asia on the basis of seismic monitoring. Fizicheskaya Mezomekhanika (Physical Mesomechanics) 11 (1), 115-122 (in Russian) [Шерман С.И., Горбунова E.A. Волновая природа активизации разломов Центральной Азии на базе сейсмического мониторинга // Физическая мезомеханика. 2008. Т. 11. № 1. С. 115-122].

Sidorov V.A., Kuz'min Y.O., 1989. Spatial-temporal characteristics of modern dynamics of the geophysical medium in seismically active and aseismic regions. In: M.A. Sadovsky (Ed.), Discrete properties of geophysical medium. Nauka, Moscow, P. 33-47 (in Russian) [Сидоров B.А., Кузьмин Ю.О. Пространственно-временные характеристики современной динамики геофизической среды сейсмоактивных и асейсмичных областей // Дискретные свойства геофизической среды / Ред. М.А. Садовский. М.: Наука, 1989. С. 33-47].

Spirtus V.B., 2008. Investigation of geosolitons in the Crimea-Black Sea region in the models of FitzHugh-Nagumo type. Geophysical Journal 30 (5), 91-100 (in Russian) [Спиртус В.Б. Исследование геосолитонов в КрымскоЧерноморском регионе в моделях типа Фитцхью-Нагумо // Геофизический журнал. 2008. Т. 30. № 5. C. 91-100].

Spirtus V.B., 2010. Possibilities of biophysical models of FitzHugh-Nagumo type in mapping of two-dimensional migration of seismicity. Geophysical Journal 32 (1), 134-143 (in Russian) [Спиртус В.Б. Возможности биофизических моделей типа Фитцхью-Нагумо в отображении двумерной миграции сейсмичности // Геофизический журнал. 2010. Т. 32. № 1. С. 134-143].

Spirtus V.B., 2011. Features of the dynamics of seismic activity in the models of FitzHugh-Nagumo type. Geophysical Journal 3 (2), 57-63 (in Russian) [Спиртус В.Б. Особенности динамики сейсмической активности в моделях типа Фитцхью-Нагумо // Геофизический журнал. 2011. Т. 33. № 2. С. 57-63].

Stein R.S., Barka A.A., Dieterich J.H., 1997. Progressive failure on the North Anatolian fault since 1939 by earthquake stress triggering. Geophysical Journal International 128 (3), 594-604. https://doi.org/10.1111/j.1365-246X. 1997.tb05321.x.

Stepashko A.A., 2013. The structure of the lithospheric mantle of the Siberain craton and seismodynamics of deformation waves in the Baikal seismic zone. Geodynamics \& Tectonophysics 4 (4), 387-415 (in Russian) [Cтепашко A.A. Структура литосферной мантии Сибирского кратона и сейсмодинамика деформационных волн в Байкальской сейсмической зоне // Геодинамика и тектонофизика. 2013. T. 4. № 4. С. 387-415]. https://doi.org/ 10.5800/GT-2013-4-4-0108.

Takahashi K., Seno T., 2005. Diffusion of crustal deformation from disturbances arising at plate boundaries - a case of the detachment beneath the Izu Peninsula, central Honshu, Japan. Earth, Planets and Space 57 (10), 935-941. https://doi.org/10.1186/BF03351873.

Takemoto S., 1995. Recent results obtained from continuous monitoring of crustal deformation. Journal of Physics of the Earth 43 (4), 407-420. https://doi.org/10.4294/jpe1952.43.407.

Trofimenko S.V., Bykov V.G., Merkulova T.V., 2017. Space-time model for migration of weak earthquakes along the northern boundary of the Amurian microplate. Journal of Seismology 21 (2), 277-286. https://doi.org/10.1007/ s10950-016-9600-x.

Vasil'ev V.A., Romanovskii Y.M., Yakhno V.G., 1979. Autowave processes in distributed kinetic systems. Soviet Physics Uspekhi 22 (8), 615-639. https://doi.org/10.1070/PU1979v022n08ABEH005591.

Vikulin A.V., Ivanchin A.G., 1998. Rotational model of the seismic process. Tikhookeanskaya Geologiya 17 (6), 95-103 (in Russian) [Викулин А.В., Иванчин А.Г. Ротационная модель сейсмического процесса // Тихоокеанская геология. 1998. Т. 17. № 6. С. 95-103].

Vikulin A.V., Melekestsev I.V., Dinara A.R., Ivanchin A.G., Vodinchar G.M., Dolgaya A.A., Gusyakov V.K., 2012. Informationcomputational system for modeling of seismic and volcanic processes as a foundation of research on wave geodynamic phenomena. Computational Technologies 17 (3), 34-54 (in Russian) [Викулин А.В., Мелекесцев И.В., Акманова Д.Р., Иванчин А.Г., Водинчар Г.М., Долгая А.А., Гусяков В.К. Информационно-вычислительная система моделирования сейсмического и вулканического процессов как основа изучения волновых геодинамических явлений // Вычислительные технологии. 2012. Т. 17. № 3. С. 34-54].

Vikulin A.V., Vodinchar G.M., Gusyakov V.K., Melekestsev I.V., Akmanova D.R., Dolgaya A.A., Osipova N.A., 2011. Migration of seismic and volcanic activity in the stress-state zones of the most geodynamically active megastructures of the Earth. Bulletin of Kamchatka State Technical University 17, 5-15 (in Russian) [Викулин А.В., Водинчар Г.М., Гусяков В.К., Мелекесцев И.В., Акманова Д.Р., Долгая А.А., Осипова Н.А. Миграция сейсмической и вулканической активности в зонах напряженного состояния вещества наиболее геодинамически активных мегаструктур Земли // Вестник КамчатГТУ. 2011. Вып. 17. С. 5-15].

Vilkovich E.V., Guberman Sh.A., Keilis-Borok V.I., 1974. Waves of tectonic strain in large faults. Doklady AN SSSR 219 (1), 77-80 (in Russian) [Вилькович Е.В., Губерман Ш.А., Кейлис-Борок В.И. Волны тектонических деформаций на крупных разломах // Доклады АН СССР. 1974. Т. 219. № 1. С. 77-80].

Vilkovich E.V., Shnirman M.G., 1982. Waves of migration of epicenters (examples and models). In: V.I. Keilis-Borok, A.L. Levshin (Eds.). Mathematical models of the Earth's structure and earthquake prediction. Computational Seismology, vol. 14. Nauka, Moscow, p. 27-37 (in Russian) [Вилькович Е.В., Шнирман М.Г. Волны миграции эпицентров (примеры и модели) // Математические модели строения Земли и прогноза землетрясений / Ред. В.И. Кейлис-Борок, А.Л. Левшин. Вычислительная сейсмология. Вып. 14. М.: Наука, 1982. С. 27-37]. 
Wang S., Zhang Z., 2005. Plastic-flow waves ("slow-waves") and seismic activity in Central-Eastern Asia. Earhquake Research in China 19 (1), 74-85.

Whitham G., 1977. Linear and Nonlinear Waves. Mir, Moscow, 622 p. (in Russian) [Уизем Дж. Линейные и нелинейные волны. М.: Мир, 1977. 622 с.].

Yamashina K., 1989. Volcanic eruptions and crustal deformation in subduction zones. Journal of the Geodetic Society of Japan 35 (2), 257-261.

Yoshida A., 1988. Migration of seismic activity along intraplate seismic belts in the Japanese islands. Tectonophysics 145 (1-2), 87-99. https://doi.org/10.1016/0040-1951(88)90318-6.

Yoshioka S., Matsuoka Y., Ide S., 2015. Spatiotemporal slip distributions of three long-term slow slip events beneath the Bungo Channel, southwest Japan, inferred from inversion analyses of GPS data. Geophysical Journal International 201 (3), 1437-1455. https://doi.org/10.1093/gji/ggv022.

Žalohar J., 2018. The Omega-Theory: A New Physics of Earthquakes. Developments in Structural Geology and Tectonics, vol. 2. Elsevier, Amsterdam, 558 p.

Zuev L.B., Barannikova S.A., Zhigalkin V.M., Nadezhkin M.V., 2012. Laboratory observation of slow movements in rocks. Journal of Applied Mechanics and Technical Physics 53 (3), 467-470. https://doi.org/10.1134/S00218944120 30200.

Zuev L.B., Danilov V.I., 2003. Slow autowave processes during deformation of solids. Fizicheskaya Mezomekhanika (Physical Mesomechanics) 6 (1), 75-94 (in Russian) [Зуев Л.Б., Данилов В.И. Медленные автоволновые процессы при деформации твердых тел // Физическая мезомеханика. 2003. Т. 6. № 1. С. 75-94].

Zykov V.S., 1984. Modeling of Wave Processes in Excitable Media. Nauka, Moscow, 168 p. (in Russian) [Зыков B.C. Моделирование волновых процессов в возбудимых средах. М.: Наука, 1984. 168 с.].

Виктор Геннадьевич Быков, докт. физ.-мат. наук

Институт тектоники и геофизики им. Ю.А. Косыгина ДВО РАН

680000, Хабаровск, ул. Ким Ю Чена, 65, Россия

\e-mail: bykov@itig.as.khb.ru

ORCID ID https://orcid.org/0000-0002-0637-0112

Victor G. Bykov, Doctor of Physics and Mathematics

Yu.A. Kosygin Institute of Tectonics and Geophysics, Far East Branch of RAS

65 Kim Yu Chen Street, Khabarovsk 680000, Russia 